\title{
A study on vehicle Noise Emission Modelling: Correlation with air pollutant emissions, impact of kinematic variables and critical hotspots
}

\author{
Antonio Pascale, Paulo Fernandes, Claudio Guarnaccia, Margarida C. Coelho
}

\begin{abstract}
:
This work proposes a methodology suitable for analysing the sound power levels $\left(\mathrm{L}_{\mathrm{w}}\right)$, and carbon dioxide $\left(\mathrm{CO}_{2}\right)$ and nitrogen oxides (NOx) emissions along a travel, and consequentially assessing the related critical hotspots. The estimation of noise and pollutant emissions from six vehicles driven along three different routes (one National Road and two highways) was conducted, in combined way, through seven Noise Emissions Models (NEMs) and Vehicle Specific Power (VSP) methodology, respectively. The inputs required by the models (namely, vehicle speed and acceleration and road grade) were extrapolated from On-Board Diagnostic (OBD) system and Global Positioning System (GPS) data recorded during monitoring campaigns. The specificities of each model were analysed, and the role played by the kinematic variables in noise and exhaust emissions assessment was highlighted. Results show that all the tested NEMs estimated higher noise levels on the highways, while VSP predicted higher emissions on the National Road. This happens because speed is the main input variable in NEMs, while acceleration has an impact on noise estimation in the low-speed range (below $50 \mathrm{~km} / \mathrm{h}$ ). For pollutant emissions evaluation, acceleration plays a fundamental role also at high-speed range, where a transition from a cruising condition to an acceleration phase leads to significant variations in terms of VSP values. $\mathrm{L}_{\mathrm{w}}$ values, estimated with NEMs that use acceleration correction terms, present positive moderateto-high correlation with VSP ones. Moreover, the models that neglect acceleration in noise estimation fail to recognize traffic control treatments as critical hotspots.
\end{abstract}

Keywords: Noise Emission Models; Vehicle Specific Power; Kinematic parameters; Critical hotspots

\section{Introduction and research objectives}

Noise and air pollution are the two most important environmental issues in Europe (European Environment Agency, 2017) and the road transport sector strongly impacts on them. In fact, the European Environment Agency estimated that around 20\% of population is exposed to traffic related noise levels exceeding the limits (European Environment Agency, 2020). In absolute terms, this means that 113 million people are exposed to day-evening-night noise levels $\left(\mathrm{L}_{\mathrm{den}}\right)$ exceeding $55 \mathrm{dBA}$ (European Environment Agency, 2020).

Road transport sector negatively impacts on air pollution as well, together with industry, agriculture and the using of fossil fuels for electricity generation (European Environment Agency, 2019a). It contributes to the $28 \%$ of the total emissions of nitrogen oxides (NOx) (European Environment Agency, 2018) and, although a decrease of Greenhouse Gases (GHG) emissions has been observed in several sectors since 1990, the transport one constitutes an exception (European Environment Agency, 2019b).

Many studies were conducted to investigate the negative effects of noise and air pollution on human health. Particularly, as analysed by Singh et al. (2018), the exposure to noise levels 
exceeding $50 \mathrm{dBA}$ leads to face sleep disorders and, consequentially, morning tiredness and lack of concentration. While Banerjee (2013) highlighted how the prolongated exposure to Lden values exceeding the limits enlarges the risk of hypertension by $60 \%$, and consequentially the onset of coronary artery issues and heart failures, Halonen et al. (2017) studied the relationship between the carotid intima-media thickness (cITM) and the exposure to night noise levels, finding a positive correlation between them. This could cause in turn stroke and coronary illness, since cITM is a hazardous component of the aforesaid diseases. Babisch (2014) verified that the stress hormones production increases with the noise exposure. As consequence of that, the heart contractions are more frequent, rapid and forceful causing in turn several complications such as systolic, diastolic and main arterial pressure increasing and ventricles damages.

Peel et al. (2013) pointed out that NOx particles can reach the lungs and cause pulmonary infections, bronchitis, emphysema, asthma, suppression of the immune system and heart complications, while Pedersen et al. (2017) showed how the exposure to high nitrogen dioxides $\left(\mathrm{NO}_{2}\right)$ concentrations during the first pregnancy trimester strongly increases the risk of preeclampsia and complications. Furthermore, Jacobson et al. (2019) conducted a review study on the main direct problems caused by carbon dioxide $\left(\mathrm{CO}_{2}\right)$ on human health. The prolongate exposure to $\mathrm{CO}_{2}$ concentrations between 2000 and 4000 parts per million (ppm) is associated with inflammations and problems in maintaining the attention. Moreover, $\mathrm{CO}_{2}$ concentrations between 2000 and $3000 \mathrm{ppm}$ could be the cause of loss of mineralization in the bones. Additionally, it was highlighted in the study that children who live in places with high $\mathrm{CO}_{2}$ concentration levels could face more easily growth and development problems.

The concern and the attention to the problems caused by traffic related noise and exhaust emissions have led to a notable development of models for their estimation.

Single-vehicle noise emissions can be assessed using Noise Emission Models (NEMs). They generally estimate the sound power level $\left(\mathrm{L}_{\mathrm{w}}\right)$ emitted by different categories of vehicles using kinematic input variables (De Coensel et al., 2016). Instead, the traffic noise estimation can be performed trough Road Traffic Noise Models (RTNMs). The first RTNMs were implemented between 1950 and 1960 (Quartieri et al., 2009; Steele, 2001) and are generally denominated Statistical Noise Models (SNMs). They provide formulas, for the estimation of the equivalent continuous A-weighted sound pressure level $\left(\mathrm{L}_{\mathrm{Aeq}}\right)$ related to the traffic flow, based on regressions carried out on field measurements taken in specific places. Consequentially, the results could be influenced by local conditions and vehicle-fleet compositions (Guarnaccia et al., 2018). Other RTNMs couple a NEM with a sound propagation model. This latter converts the information provided by the NEM in terms of $\mathrm{L}_{\mathrm{w}}$ into sound pressure levels $\left(\mathrm{L}_{\mathrm{p}}\right)$ at the receiver. Additionally, RTNMs can be based on simplified hypothesis related to the traffic-flow kinematic conditions (Can et al., 2008). They can assume steady-state traffic conditions where all vehicles present the same constant speed (see the methodology followed in Quartieri et al. (2010)). This approach leads to obtain easily applicable models in which the full potential of the NEM used is not exploited. Other RTNMs are able to use more information provided by the NEM, considering the speed (and in some case the acceleration) of each vehicle and the road-segment slope (see Guarnaccia (2020)). The RTNMs that consider the single-vehicle speed are also denominated microscopic, which are usually more complex, but provide better performances.

On the other hand, one of the most recognised methodology to estimate road-traffic pollutant emissions is the Vehicle Specific Power (VSP) (US EPA, 2002) that is function of speed, acceleration and road grade on a second-by-second time basis. VSP values are associated to modes that represent the driving state conditions (i.e., deceleration, low speed moving and acceleration state). Each mode is sub-sequentially related to an emission factor for different vehicles typologies and pollutants species. The emission factors are provided as means of vehicle powertrain such as gasoline (Anya et al., 2013), diesel (Fernandes et al., 2019a), and hybrid (Fernandes et al., 2021). VSP allows to estimate tailpipe emissions for each vehicle or a fleet of vehicles with similar characteristics. Since it is computed in real driving conditions, the amounts of emissions can be assigned to any road configuration or traffic control treatment including roundabouts (Fernandes et al., 2015a, Fernandes et al., 2015b, Fernandes et al., 2018), signalized intersections (Salamati et al., 2015), speed control traffic lights (Coelho et al., 2009), and stop controlled intersections (Fernandes et al., 2017). 
Some studies were presented in literature with the aim to compare different noise models. For instance, Graziuso et al. (2020) conducted a comparison between NEMs on the base of two novel noise parameters: the average and total sound power levels emitted during a trip. However, the presence of acceleration and road grade correction terms was not considered in the analyses, as well as the number of trips performed was limited. Can and Aumond (2018) compared different traffic noise models and their way to consider the acceleration. Input data (i.e., vehicles' speed and acceleration) were extracted from a 32-minute video record and the estimated noise levels were compared with the recorded ones. Moreover, several works on single-vehicle exhaust emissions were carried out; for instance, O'Driscoll et al. (2018) characterised the on-road CO2 and NOx emissions for several types of gasoline, diesel and hybrid vehicles, while Yuan et al. (2019) found CO2 and NOx emission rates for four gasoline vehicles through VSP. Fernandes et al., by following the same approach, characterised $\mathrm{CO}_{2}$ and $\mathrm{NOx}$ emissions for four diesel vehicles both through VSP methodology and internal observable engine variables (Fernandes et al., 2019a) and found the emission factors for a hybrid vehicle (Fernandes et al., 2021).

The presence in literature of relevant research focused on integrated assessment of traffic noise and pollutant emissions is scant. Fernandes et al. quantified noise and pollutant emissions in proximity of three different roundabout layouts (Fernandes et al., 2020) through VSP and Quartieri et al. noise model, respectively; and evaluated the noise and exhaust emissions impacts on Portuguese intercity corridors by using an approach based on the external costs (Fernandes et al., 2019b). Furthermore, the needing to conduct deeper and multidisciplinary works on noise and pollutant emissions assessment remains a fundamental aspect, how also highlighted in Can et al. (2020).

From the above-discussed facts, it emerges that: i) the assessment of single-vehicle noise emissions and the consequent comparison between the employed NEMs were performed by only considering the influence of speed and on a limited number of trips; ii) there is scarce attention in literature on the role played by kinematic variables in noise and pollutant emissions estimation; iii) few studies were dedicated to a combined evaluation of noise and exhaust emissions in different types of roads, with the identification of critical hotspots. Therefore, this work aims to fulfil these gaps by: 1) conducting a strict and rigorous analysis on the way different NEMs consider the variables that affect noise, discussing their specificities and characteristics, and comparing their noise estimations obtained from real driving kinematic data input retrieved from several trips; 2) analysing the impact of kinematic variables on noise and pollutant emissions evaluation through NEMs and VSP, respectively; 3) assessing and comparing critical hotspots in terms of noise and pollutant emissions along a National Road and two highways.

Hence, the research may be valuable for two main reasons. Firstly, it can provide useful insights and highlight the characteristics of NEMs that in turn significantly affect the forecasting goodness of the NEMs themselves in terms of sound pressure levels in different traffic conditions, when coupled with a sound propagation model. Secondly, the research provides an easily replicable methodology for the assessment of noise and exhaust emissions along a trip based on kinematic and road information. This can be useful for the development of maps for detection of critical hotspots and thus, helpful for policymakers in the enaction of sustainable action plans.

\section{Methodology}

The methodology followed in this work is illustrated in Fig. 1. First, field data were collected in different types of roads, and kinematic parameters were then used as input in VSP and NEMs. Thus, noise locations and emission hotspots were evaluated and a rigorous comparison among NEMs and a strict evaluation of kinematic variables impact on NEMs and VSP were performed. 


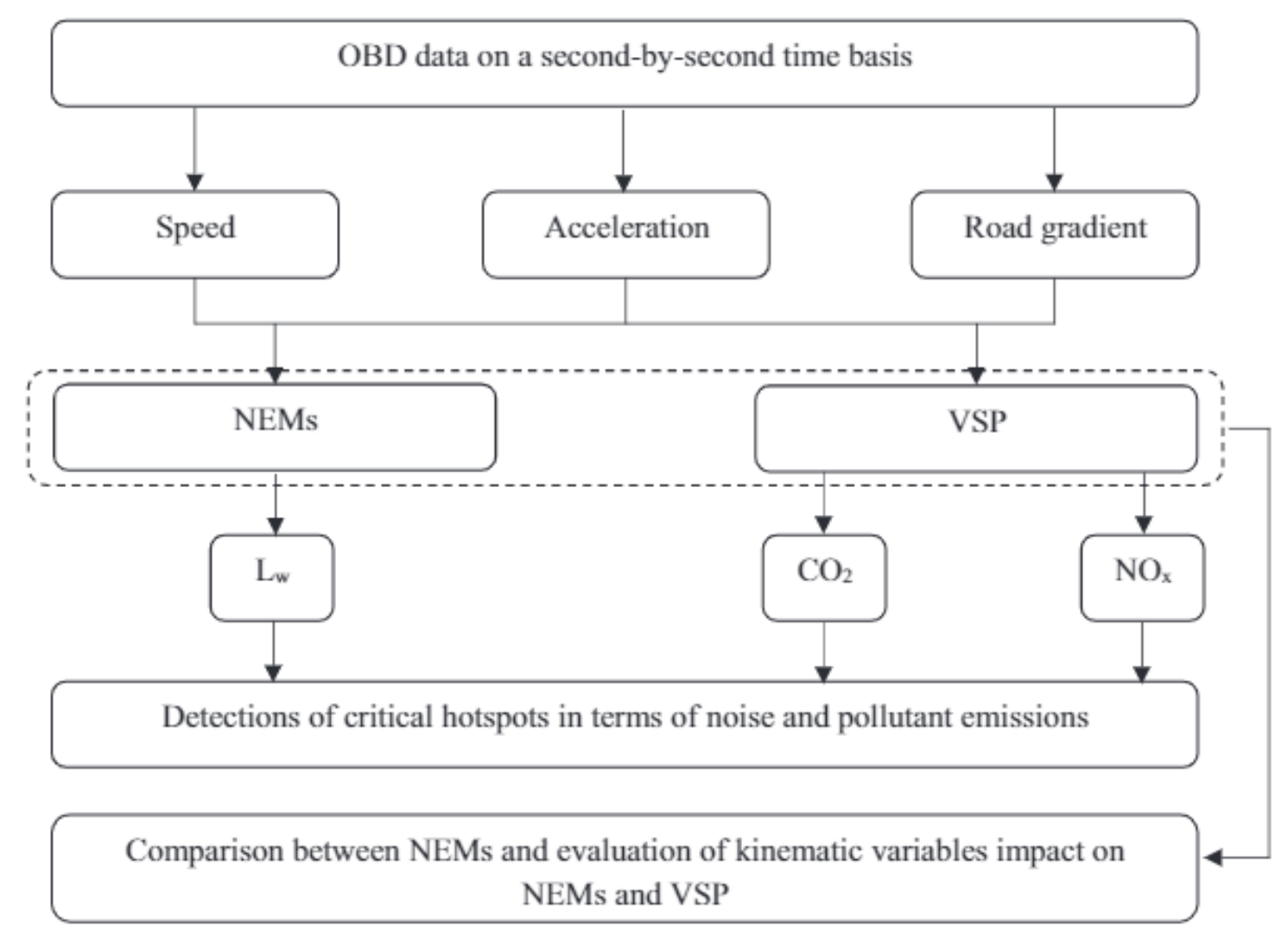

Fig. 1. Methodology overview.

\subsection{Data collection}

Six different passenger cars were equipped with an On-Board Diagnostic system (OBDII) and driven by six drivers (Table 1).

Table 1. Vehicles characteristics.

\begin{tabular}{llrlrlr}
\hline $\begin{array}{l}\text { Vehicle } \\
\text { ID }\end{array}$ & Motorisation & Year & $\begin{array}{l}\text { European } \\
\text { Emission } \\
\text { Standard }\end{array}$ & $\begin{array}{l}\text { Milleage } \\
{[\mathrm{km}]}\end{array}$ & $\begin{array}{l}\text { Engine size } \\
{\left[\mathrm{cm}^{3}\right]}\end{array}$ & $\begin{array}{l}\text { Power } \\
{[\mathrm{hp}]}\end{array}$ \\
\hline V1 & Diesel & 2006 & Euro 4 & 180,000 & 1800 & 125 \\
V2 & Diesel & 2017 & Euro 6 & 32,000 & 1300 & 75 \\
V3 & Diesel & 2017 & Euro 6 & 23,000 & 1500 & 102 \\
V4 & Diesel & 2018 & Euro 6 & 25,000 & 1460 & 90 \\
V5 & Gasoline-electric & 2019 & Euro 6 & 7500 & 1800 & 122 \\
& hybrid & & & & & 100 \\
V6 & Gasoline & 2019 & Euro 6 & 2500 & 1000 & 100 \\
\hline
\end{tabular}

Three distinct routes connecting two Portuguese cities, Angeja and Estarreja, were chosen and travelled in both directions: i) N109 National Road (one lane by travelling direction); ii) A29 highway (two lanes by travelling direction) and iii) A1 highway (two lanes by travelling direction). The road segments travelled along the N109, A29 and A1 have a length respectively equal to $11.8,15.0$ and $17.0 \mathrm{~km}$. 
Prior to on-road data collection, the minimum sample size (number of trips) on each route was determined. Eq. (1) was used to compute sample sizes based on the standard deviation of the route-specific travel time and a tolerable error (Ott and Longnecker, 2008).

$$
N=\left(\frac{t \times c v}{\varepsilon}\right)^{2},
$$

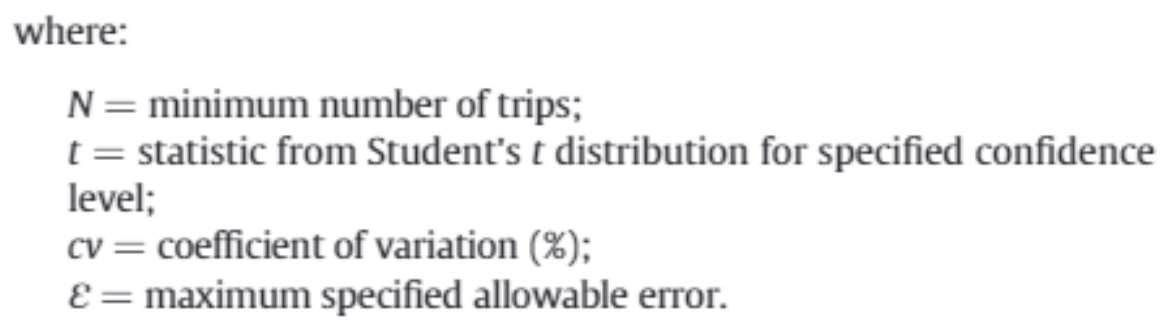

The $c v$ for travel times depends on Average Daily Traffic (ADT) per lane in highways and the traffic signal density in arterial road (Ott and Longnecker, 2008). Some design manuals provide typical minimum sample sizes for various combinations of confidence levels and acceptable relative error in different types of roads (Ott and Longnecker, 2008). Since ADT on A29 and A1 study segments was lower than 15,000 daily vehicles per lane and 20,000 daily vehicles per lane (Instituto da Mobilidade e dos Transportes, 2018), respectively, and traffic signal density was lower than 3 traffic lights per $1.6 \mathrm{~km}$ segment in $\mathrm{N} 109$, the minimum number to ensure a $95 \%$ confidence level with less of $10 \%$ error is 8 trips (Turner, 1998).

A total of 29, 16 and 14 trips were conducted respectively on the National Road, A29 and A1 and, in total, more than $850 \mathrm{~km}$ were covered. The National Road presents urban and rural segments in which speed limit is set to $50 \mathrm{~km} / \mathrm{h}$ and $70 \mathrm{~km} / \mathrm{h}$, respectively, with several traffic singularities, namely six roundabouts, one speed-control traffic signal, one stop-controlled intersection and eight signalized intersections. The speed limit on the two highways is set to 120 $\mathrm{km} / \mathrm{h}$ and $\mathrm{A} 1$ has toll booths containing both conventional and electronic pay tolls.

Moreover, the road slope ranges: i) from $-1.5 \%$ to $1 \%$ on the National Road, with presence of small stretches at $4.5 \%$; ii) from $-1.7 \%$ to $1.6 \%$ on the A29, with short segments at $-3 \%$ and $5 \%$; iii) from $-1.8 \%$ to $1.9 \%$ on the A1, with few stretches at $5 \%$. More details about the studied routes can be found in Fernandes et al. (2019b).

Speed was extracted from the OBD data on a second-by-second time basis. The acceleration was computed from speed values using the backward finite difference.

In addition, road slope was estimated for each $500 \mathrm{~m}$ road section using Global Positioning System (GPS) information, as suggested in Sandhu and Frey (2013). All the variables were used to compute the $\mathrm{L}_{\mathrm{w}}$ and VSP values, $\mathrm{CO}_{2}$ and NOx emissions produced second-bysecond during each trip by applying different NEMs and VSP methodology, respectively.

The results were analysed to conduct a comparison between NEMs and to evaluate the impact of kinematic variables on NEMs and VSP methodology. Moreover, maps were created through a GIS platform to detect critical hotspots in terms of noise and pollutant emission along the paths.

\subsection{Noise Emission Models}

The Noise Emission Models used for the analysis are shortly presented in this section. Seven different NEMs were considered (Table 2). Six of them (Dutilleux et al., 2010; Heutschi, 2004; Kephalopoulos et al., 2012; Lelong, 1999; Watts, 2005; Yamamoto, 2010) are consolidated NEMs presented in literature and followed by some national regulations, while the last model (Vehicle Noise Specific Power - VNSP) was developed by the authors (Pascale et al., 2020) with the purpose to follow the methodology proposed in VSP and provide the sound power level 
formulation based on vehicle powertrain. The presentation of the models is limited to the formulas used for the sound power level estimation produced by passenger cars. Presences of correction terms related to acceleration phases and road grade are discussed in 2.2.1 Acceleration correction terms, 2.2.2 Road grade correction terms, respectively.

Table 2. Noise Emission Models overview.

\begin{tabular}{|c|c|c|c|c|c|c|}
\hline Model & Reference & Spectrum information & $\begin{array}{l}\text { Division between } \\
\text { engine and rolling } \\
\text { noise contribution }\end{array}$ & $\begin{array}{l}\text { Presence of } \\
\text { acceleration } \\
\text { correction term }\end{array}$ & $\begin{array}{l}\text { Presence of road } \\
\text { grade } \\
\text { correction term }\end{array}$ & $\begin{array}{l}\mathrm{L}_{\mathrm{w}} \text { passenger car } \\
\text { formula }\end{array}$ \\
\hline Lelong & (Lelong, 1999) & $\begin{array}{l}\text { Formulation valid for } \\
\text { the entire frequencies } \\
\text { spectrum }\end{array}$ & No & $\begin{array}{l}\text { Yes (valid for } a> \\
0 \mathrm{~m} / \mathrm{s}^{2} \text { and } v<25 \\
\mathrm{~km} / \mathrm{h} \text { ) }\end{array}$ & No & $L_{w}=53.6+26.8 \log (v)$ \\
\hline Harmonoise & (Watts, 2005) & $\begin{array}{l}\text { Coefficients given for } \\
\text { third band of octave } \\
\text { from } 25 \mathrm{~Hz} \text { to } 10 \mathrm{kHz}\end{array}$ & Yes & $\begin{array}{l}\text { Yes }(\text { valid for a } \epsilon \\
\left.[-2,2] \mathrm{m} / \mathrm{s}^{2}\right)\end{array}$ & No & 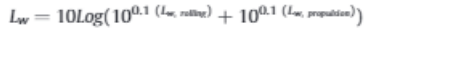 \\
\hline NMPB & $\begin{array}{l}\text { (Dutilleux et al., } \\
\text { 2010) }\end{array}$ & $\begin{array}{l}\text { Formulation valid for } \\
\text { the entire frequencies } \\
\text { spectrum }\end{array}$ & Yes & Yes & No & 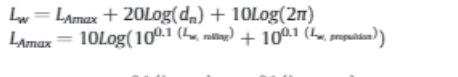 \\
\hline CNOSSOS & $\begin{array}{l}\text { (Kephalopoulos } \\
\text { et al., 2012) }\end{array}$ & $\begin{array}{l}\text { Coefficients given for } \\
\text { each band of octave } \\
\text { from } 125 \mathrm{~Hz} \text { to } 4 \mathrm{kHz}\end{array}$ & Yes & $\begin{array}{l}\text { Valid in proximity } \\
\text { of roundabouts } \\
\text { and intersections }\end{array}$ & $\begin{array}{l}\text { Yes (valid both } \\
\text { for uphill and } \\
\text { downhill roads) }\end{array}$ & 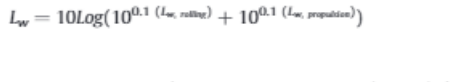 \\
\hline SonRoad & $\begin{array}{l}\text { (Heutschi, } \\
\text { 2004) }\end{array}$ & $\begin{array}{l}\text { Formulation valid for } \\
\text { the entire frequencies } \\
\text { spectrum }\end{array}$ & No & No & $\begin{array}{l}\text { Yes (valid for } \\
\text { uphill roads) }\end{array}$ & 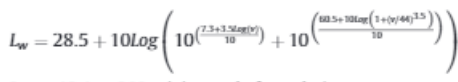 \\
\hline AS] & $\begin{array}{l}\text { (Yamamoto, } \\
\text { 2010) }\end{array}$ & $\begin{array}{l}\text { Formulation valid for } \\
\text { the entire frequencies } \\
\text { spectrum }\end{array}$ & No & No & No & $\begin{array}{l}L_{w}=46.4+30 \log (v), \text { steady formulation } \\
L_{w}=82+10 \log (v), \text { non steady formulation }\end{array}$ \\
\hline VNSP & $\begin{array}{l}\text { (Pascale et al., } \\
2020 \text { ) }\end{array}$ & $\begin{array}{l}\text { Formulation valid for } \\
\text { the entire frequencies } \\
\text { spectrum }\end{array}$ & No & No & No & 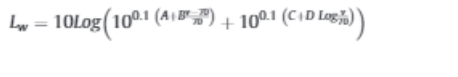 \\
\hline
\end{tabular}

\subsubsection{Acceleration correction terms}

It must be stressed that Lelong, Harmonoise and NMPB models have different ways to consider acceleration and deceleration phases. Lelong model assumes the same formulation indicated in Table 2 in the case of deceleration phase. If the acceleration values are positive and the speed is below $25 \mathrm{~km} / \mathrm{h}$, then the $\mathrm{L}_{\mathrm{w}}$ is set to $90.5 \mathrm{dBA}$.

Harmonoise adds a corrective term to propulsion sound power level ( $\mathrm{L}_{\mathrm{w}, \text { propulsion}}$ ) contribution valid for acceleration values between -2 and $2 \mathrm{~m} / \mathrm{s}^{2}$. The aforesaid correction term is identically equal to 4.4 times the acceleration value (expressed in $\mathrm{m} / \mathrm{s}^{2}$ ).

NMPB model uses different coefficients for the estimation of the rolling and propulsion noise contributions, based on acceleration signs and speed ranges. The reader can refer to (Besnard et al., 2009) to check all coefficients values. Additionally, in contrast with Harmonoise model, NMPB tends to emphasize the noise emissions in the deceleration phases, due to the engine brake associated noise.

Among the models that present correction terms related to the acceleration and deceleration phases, also CNOSSOS appears. It proposes correction terms to apply both to the propulsion and rolling noise contribution parts, for each band of octave $\left(\Delta \mathrm{L}_{\mathrm{w}, \mathrm{p}, \mathrm{acc}, \mathrm{i}}\right.$ and $\Delta \mathrm{L}_{\mathrm{w}, \mathrm{r}, \mathrm{acc}, \mathrm{i},}$ respectively). However, they can be used just when the vehicle is in proximity of roundabouts and crossings (Kephalopoulos et al., 2012). In fact, the acceleration does not explicitly appear in them and everything is ruled by the vehicle-intersection distance:

$$
\begin{aligned}
& \Delta L_{w, p, a c c, i}=C_{p} \max \left(1-\frac{|x|}{100} ; 0\right), \\
& \Delta L_{w, r, a c c, i}=C_{r} \max \left(1-\frac{|x|}{100} ; 0\right),
\end{aligned}
$$

where $C_{p}$ and $C_{r}$ are coefficients that change according to the intersection type (i.e., roundabout or crossing), while $x$ is the distance in meters between the vehicle and the intersection itself. 
In this work, the corrections proposed by CNOSSOS through Eqs. (2), (3) will not be considered, inasmuch the absence of acceleration in the formula does not allow to take in account the vehicle acceleration phases in each point and in each time period of the trip, but just in proximity of an intersection. The authors calculated the noise emission provided by CNOSSOS by using the acceleration correction terms, in the National Road (i.e., the only trip with intersections) and found no significant differences.

\subsubsection{Road grade correction terms}

CNOSSOS and SonRoad models can consider road grade effect on noise. The former adds a correction term to propulsion sound power level contribution as follow:

$$
\begin{aligned}
& L_{\text {w.propulsion }}=10 \log _{10}\left(\sum_{i} 10^{\Lambda_{i p}+B_{i p}\left(\frac{v-70}{T 0}\right)+\Delta l_{\text {grate }}}\right), \\
& \Delta L_{\text {grade }}= \begin{cases}\frac{\min (12 \% ;-\mathrm{s})-6 \%}{1 \%} & \text { for } \mathrm{s}<-6 \% \\
0 & \text { for }-6 \% \leq \mathrm{s} \leq 2 \%, \\
\frac{\min (12 \% ; \mathrm{s})-2 \%}{1.5 \%} \frac{\mathrm{v}}{100} & \text { for } \mathrm{s}>2 \%\end{cases}
\end{aligned}
$$

where: $\Delta \mathrm{L}_{\text {grade }}-$ road grade correction term equal for all octave bands; $s$-road grade [\%].

SonRoad introduces a correction term for the slope $(\Delta \mathrm{S})$ as well, thus its formulation modifies as follow:

$$
L_{w}=28.5+10 \log _{10}\left(10^{\frac{73+35 \log _{10}(v)}{10}}+10^{\frac{60.5+10 \log _{10}\left(1+\left(\frac{y}{49}\right)^{3.5}\right)+\Delta_{S}}{10}}\right),
$$

The correction term is valid only for uphill road. It is identically equal to $0.8 \mathrm{~g}$, where $g$ is the road slope expressed in percentage.

It must be stressed that CNOSSOS model, in contrast with SonRoad, provides correction terms valid also for downhill roads. The sound power levels computed with CNOSSOS on downhill roads are higher than those at flat ones, fixing speed. This happens because the engine brake contribution has a particular role in vehicle noise emissions in downhill driving operation.

\subsection{Noise assessment}

The sound power level was computed on a second-by-second time basis using the NEMs introduced in the previous sections. The kinematic information in terms of speed from the OBD was used for all the models, while vehicle-acceleration was used for Lelong, Harmonoise and NMPB models, and road grade data for CNOSSOS and SonRoad.

The second-by-second evaluation of $\mathrm{L}_{\mathrm{w}}$ during a trip allows to define another noise parameter: the average sound power level, proposed in Graziuso et al. (2020). It represents the average sound power level per second emitted during a trip and is defined as:

$$
L_{w, a v e}=10 \log _{10}\left[\frac{1}{\Delta T} \sum_{i} 10^{\frac{t_{w j}}{10}} \Delta t\right] \text {, }
$$

where:

$L_{w . a v e}-$ average sound power level [dBA];

$\Delta T$ - duration of the trip [s];

$L_{w, i}$ - sound power level related to the second $i[\mathrm{dBA}]$;

$\Delta t$ - time basis equal to $1 \mathrm{~s}$. 
This parameter was computed for each model and for each trip. The $\mathrm{L}_{\mathrm{w}, \text { ave }}$ related to each NEM and road were sub-sequentially averaged as follow:

$$
\bar{L}_{w, a v e, j, k}=\frac{1}{N} \sum_{m=1}^{N} L_{w, a v e, j, m},
$$

where $j$ is the index of the noise model, $k$ is the index of the selected road and $N$ is total number of the trips on the selected road.

\subsection{Vehicle Specific Power}

Vehicle Specific Power represents the vehicle instantaneous power per unit mass (US EPA, 2002). The vehicle engine uses instantaneous power to contrast the rolling resistance and the aerodynamic drag and to enlarge vehicle-related kinematic and potential energies (Zhai et al., 2020):

$$
V S P=\frac{1}{m}\left[\frac{d}{d t}(K E+P E)+F_{\text {rolling }} v+F_{\text {aerodynamic }} v\right],
$$

where:

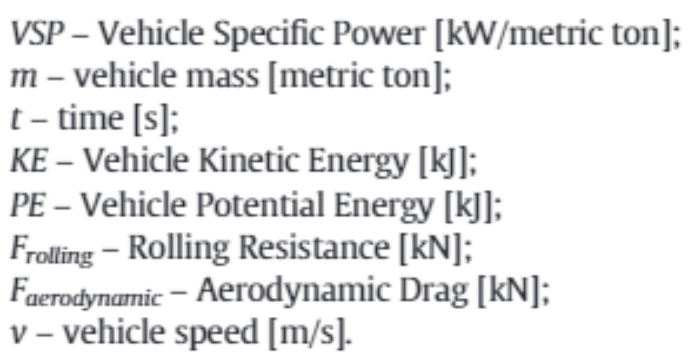

In the case of a passenger car, Eq. (9) can be simplified and directly related to vehicle speed and acceleration and to road slope, as follows (Zhai et al., 2020):

$$
\begin{aligned}
\text { VSP }= & v\left[1.1 a+9.81 \sin \left(\arctan \left(\frac{\text { grade }}{100}\right)\right)+0.132\right] \\
& +0.000302 v^{3},
\end{aligned}
$$

where:

$$
\begin{aligned}
& a \text { - vehicle acceleration }\left[\mathrm{m} / \mathrm{s}^{2}\right] \text {; } \\
& \text { grade - road grade [\%]. }
\end{aligned}
$$

Then, VSP is divided in fourteen values-ranges that represent a mode. The first two modes refer to deceleration phases, the third to a condition in which the vehicle is moving at low speed, while the other modes are related to positive acceleration phases at moderate to high speeds. Each mode is in turn associated to an emission factor for each pollutant species (i.e., carbon monoxide, $\mathrm{CO}_{2}$, NOx and hydrocarbons). As mentioned in Section 1, the emission factors are provided for categories of vehicles based also on the powertrain (i.e., gasoline, diesel, hybrid).

VSP was calculated second-by-second for each travel using the OBD data and road slope information using more than $48,000 \mathrm{~s}$ of OBD data. VSP values were associated to the each one of fourteen modes and subsequentially to the emission factors of six different passenger cars: four diesel, one gasoline and one hybrid electric vehicle (Table 1).

The on-board emissions data were acquired previously by an integrated Portable Emissions Measurement System (PEMS) at the studied locations and testing vehicles of this study. Full details about emissions monitoring can be found elsewhere (Fernandes et al., 2019a, Fernandes et al., 2021). VSP emission factors by vehicle were calibrated using these data, as 
shown in Tables S.1 and S.2 for CO2 and NOx, respectively. Since the used PEMS does not include hydrocarbons ( $\mathrm{HC}$ ) and carbon monoxide (CO) analysers, VSP emission factors of NOx and $\mathrm{CO}_{2}$ were only developed. Supplementary data file also contains the validation of VSP emission factors for $\mathrm{CO}_{2}$ (Fig. S.3) and NOx (Fig. S.4) by vehicle; the coefficients of determination $\left(R^{2}\right)$ between estimated and observed data were 0.79 or higher.

\section{Results}

The estimations in terms of noise and pollutant emissions produced during the trips at the selected roads are presented in 3.1 Noise results, 3.2 Pollutant emissions results, respectively. The different influence of the kinematic variables on noise and pollutant emissions estimation is discussed in Section 3.3. The correlation coefficients between $\mathrm{L}_{\mathrm{w}}$ and VSP values are presented in Section 3.4. Finally, maps, created through a GIS platform, are introduced in Section 3.5 with the scope of finding critical hotspots in terms of noise and emissions.

\subsection{Noise results}

Fig. 2 shows the $\bar{L}_{w, \text { ave }}$ with the related standard deviation values obtained for each model and road type by travelling direction. It must be highlighted that ASJ model was used with the non-steady formulation for noise assessment along the National Road, and with the steady formulation along the two highways.

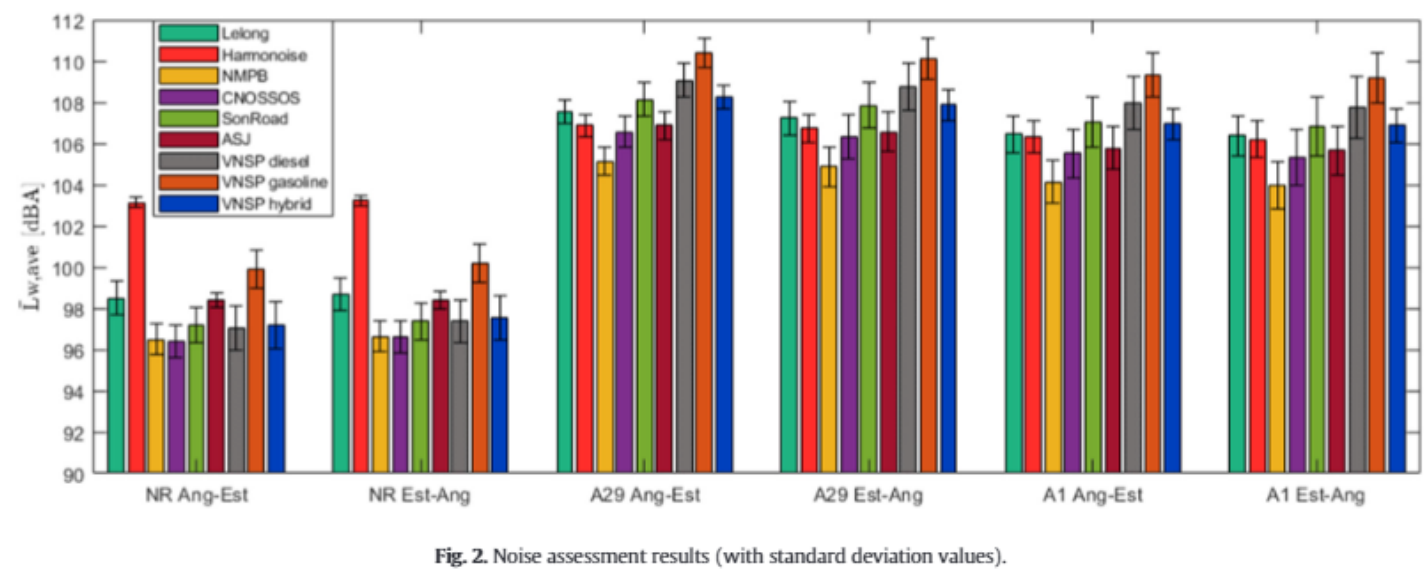

The highest values of $\bar{L}_{w, \text { ave }}$ occurred on the two highways. This can be easily explained with the higher speeds maintained compared to the National Road. Moreover, values estimated for the A1 are slightly lower than those related to A29. This could be associated with the lower average speed maintained by drivers on A1 than that related to the trips on A29. Note that A1 traffic volumes were nearly 3.4 times higher than A29 ones in the studied sections during the field data collection (see Section 2.1 for these details). The results obtained at the National Road show that Harmonoise model predicted higher values (about $5 \mathrm{dBA}$ more) compared to the other NEMs. On the other hand, the results related to A29 and A1 reveal that the differences between estimations provided by Harmonoise and the other models disappear.

The sound power level is plotted against the speed for all the employed NEMs (neglecting all the correction terms) in Fig. 3. It appears clear that Harmonoise model exhibits higher $\mathrm{L}_{\mathrm{w}}$ estimations for speeds up to $60 \mathrm{~km} / \mathrm{h}$. This justifies the results obtained with Harmonoise at the National Road, where the average speed maintained is around $45 \mathrm{~km} / \mathrm{h}$. 


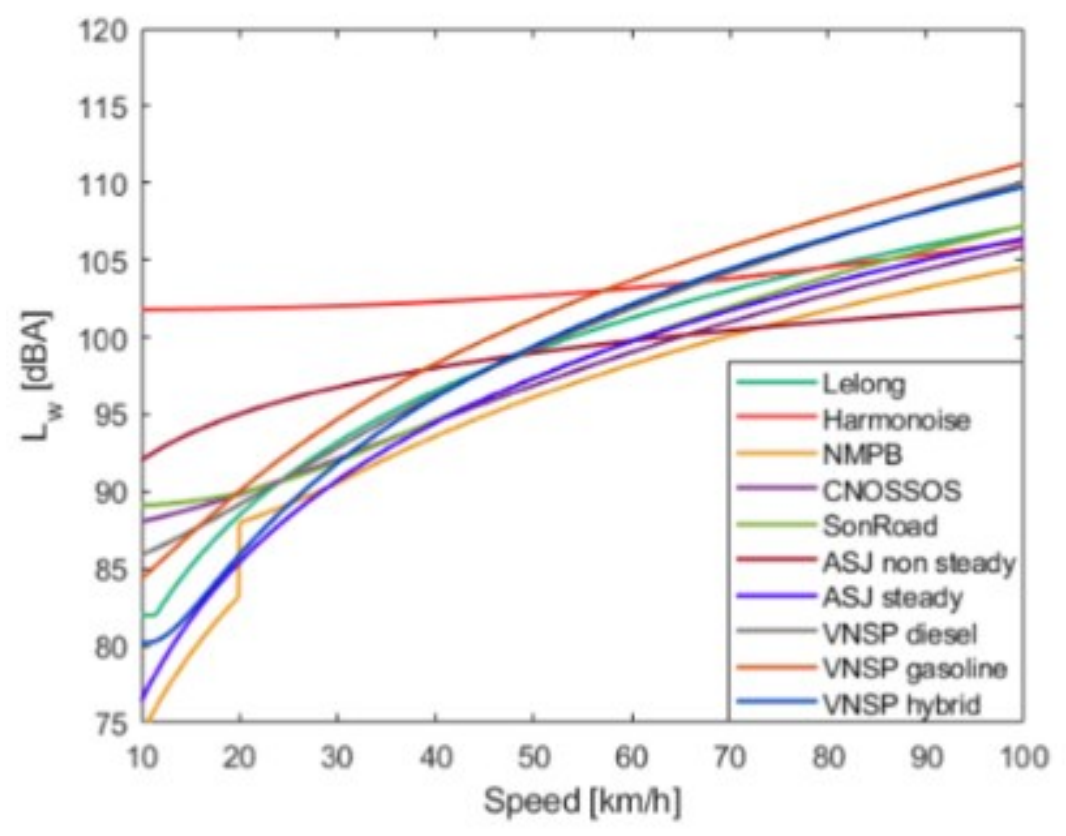

Fig. 3. Noise Emission Models comparison.

Instead, in the highway travels, where the average speed is equal to 95 and $80 \mathrm{~km} / \mathrm{h}$ for A29 and A1, respectively, the rolling noise contribution becomes predominant (Bernhard and Wayson, 2005), and the differences in noise estimation between Harmonoise and the other models vanish. Finally, VNSP is the only model that provides a classification of passenger cars based on powertrain. It is important to underline that the results of this model are not generalizable for all the diesel, gasoline, and hybrid cars but must be referred to the three different vehicles used during its calibration. For more details and to check the vehicle's characteristics used during the calibration process of VNSP, the reader can refer to (Pascale et al., 2020). It is worth mentioning that the hybrid car presents almost the same noise emissions of the diesel one. VNSP model was, in fact, calibrated with a hybrid vehicle heavier than the diesel one used (1860 and $1200 \mathrm{~kg}$, respectively). Moreover, tyres related width and diameter of the hybrid vehicle result to be greater than those of the diesel one ( $215 \mathrm{~mm}, 17 \mathrm{in}$. and $185 \mathrm{~mm}, 15 \mathrm{in}$., respectively). This had in turn repercussion on the rolling noise emission contribution, strongly affected by the above-mentioned parameters. Although the hybrid vehicle exhibits less noise emission at low speeds (about $5 \mathrm{dBA}$ less than the diesel one) because of the advantage given by the electric engine, this gap tends to vanish for speeds above $30 \mathrm{~km} / \mathrm{h}$.

The calculation for Lelong, Harmonoise and NMPB models were replicated without the acceleration correction term, as it possible to see in Table 3.

Table 3

Noise assessment results (with standard deviation values) for models used with and without acceleration correction terms.

\begin{tabular}{|c|c|c|c|c|c|c|}
\hline Road direction & NR Ang-Est & NR Est-Ang & A29 Ang-Est & A29 Est-Ang & A1 Ang-Est & A1 Est-Ang \\
\hline Model/parameter & $\bar{L}_{\text {wave }}[\mathrm{dBA}]$ & $\bar{L}_{\text {wave }}[\mathrm{dBA}]$ & $\bar{L}_{\text {wave }}[\mathrm{dBA}]$ & $\bar{L}_{\mathrm{w}, \mathrm{ave}}[\mathrm{dBA}]$ & $\bar{L}_{\text {wave }}[\mathrm{dBA}]$ & $\bar{L}_{\text {wave }}[\mathrm{dBA}]$ \\
\hline Lelong & $98.5 \pm 0.8$ & $98.7 \pm 0.8$ & $107.5 \pm 0.6$ & $107.2 \pm 0.8$ & $106.5 \pm 0.9$ & $106.4 \pm 1.0$ \\
\hline Harmonoise & $103.1 \pm 0.3$ & $103.2 \pm 0.3$ & $106.9 \pm 0.5$ & $106.7 \pm 0.7$ & $106.3 \pm 0.8$ & $106.2 \pm 0.9$ \\
\hline Harmonoise without acc. & $102.6 \pm 0.2$ & $102.6 \pm 0.2$ & $106.6 \pm 0.5$ & $106.5 \pm 0.7$ & $106.0 \pm 0.7$ & $105.9 \pm 0.8$ \\
\hline NMPB & $96.5 \pm 0.7$ & $96.6 \pm 0.7$ & $105.1 \pm 0.7$ & $104.9 \pm 0.9$ & $104.1 \pm 1.0$ & $104.0 \pm 1.1$ \\
\hline NMPB without acc. & $95.5 \pm 0.8$ & $95.6 \pm 0.8$ & $105.0 \pm 0.7$ & $104.7 \pm 0.9$ & $103.9 \pm 1.0$ & $103.8 \pm 1.1$ \\
\hline
\end{tabular}

In the case of Lelong, not appreciable differences were detected between the model used with and without acceleration correction term. In fact, Lelong, as discussed in Section 2.2.1, uses the same formula for noise assessment in deceleration, cruising and acceleration conditions for speed above $25 \mathrm{~km} / \mathrm{h}$, and the only correction for the acceleration phases is a constant value of $\mathrm{L}_{\mathrm{w}}$ valid for speed below $25 \mathrm{~km} / \mathrm{h}$. 
The differences in terms of $\bar{L}_{w, \text { ave }}$ between Harmonoise used with and without acceleration correction term are around 0.6, 0.2 and $0.3 \mathrm{dBA}$ for National Road, A29 and A1, respectively. These values become respectively $1,0.1$ and $0.2 \mathrm{dBA}$ for NMPB model. The slight differences obtained with and without acceleration correction term for both models along the two highways can be due to the stationary-driving conditions (i.e., no strong speed variations). Moreover, acceleration influence on noise is more relevant in the low-speed range (below the $50 \mathrm{~km} / \mathrm{h}$ ) than high one. At high speeds, in fact, the engine noise contribution, which is affected by acceleration manoeuvres, is covered by the rolling one.

On the National Road, NMPB presents higher differences with the model used without correction term than Harmonoise. This can be related to the way how they consider the acceleration: Harmonoise increases and decreases $L_{w}$ for positive and negative acceleration values, respectively. Hence, the deceleration phases tend to balance the acceleration ones. This does not happen for NMPB model (as marked in Section 2.2.1).

The calculations were also replicated for CNOSSOS and SonRoad by omitting the road slope correction term. Considering that the streets of the case study are almost flat, no significant variations were noted.

\subsection{Pollutant emissions results}

The average values and standard deviation related to the emissions per kilometre of $\mathrm{CO} 2$ and NOx are shown in Fig. 4 for each vehicle and street, using VSP methodology.
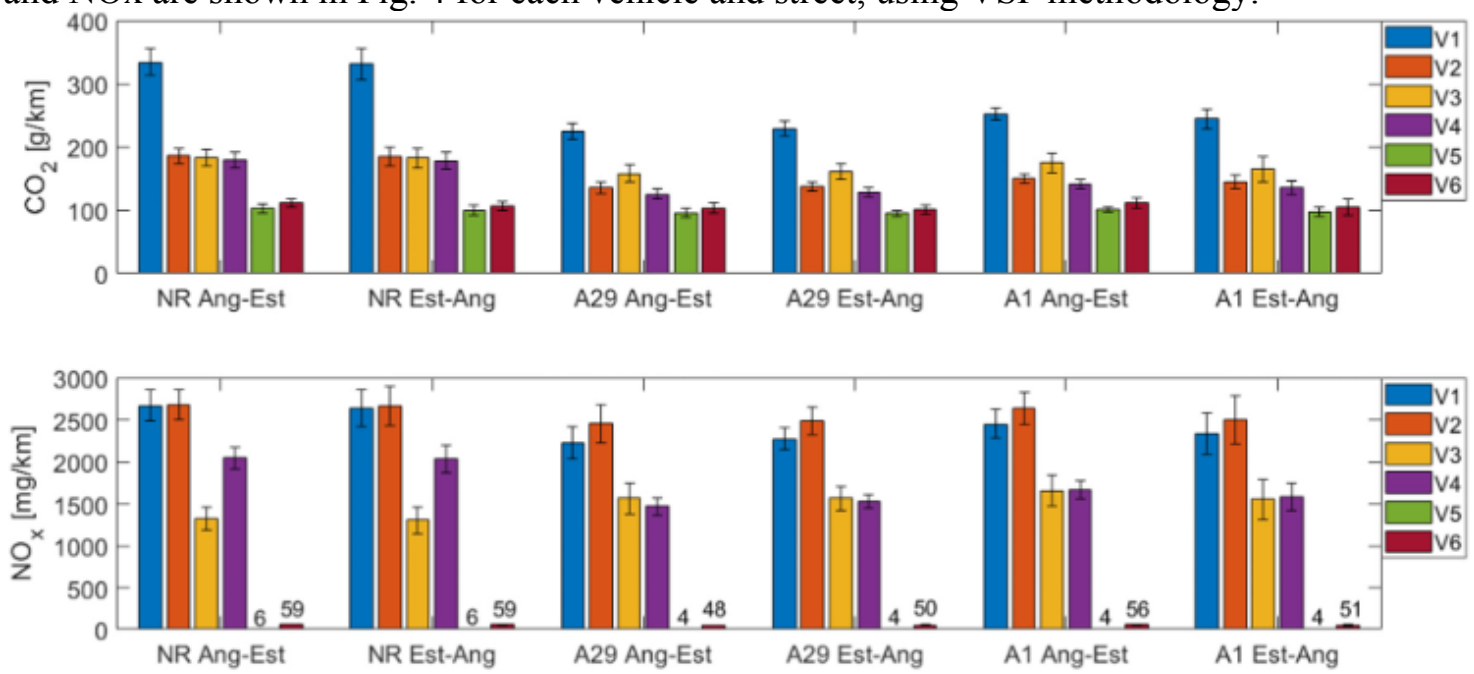

Fig. 4. Pollutant emission assessment results (with standard deviation values): a) $\mathrm{CO}_{2}$ per unit distance; and $b$ ) $\mathrm{NO}_{\mathrm{x}}$ per unit distance.

It is interesting to note that the emissions per kilometre in terms of $\mathrm{CO}_{2}$ and $\mathrm{NOx}$ are estimated to be tendentially higher on the National Road, as compared to highway roads. These results come from the speed and acceleration distribution and consequentially the VSP modes distribution in each route (Fig. 5, Fig. 6). 
a)
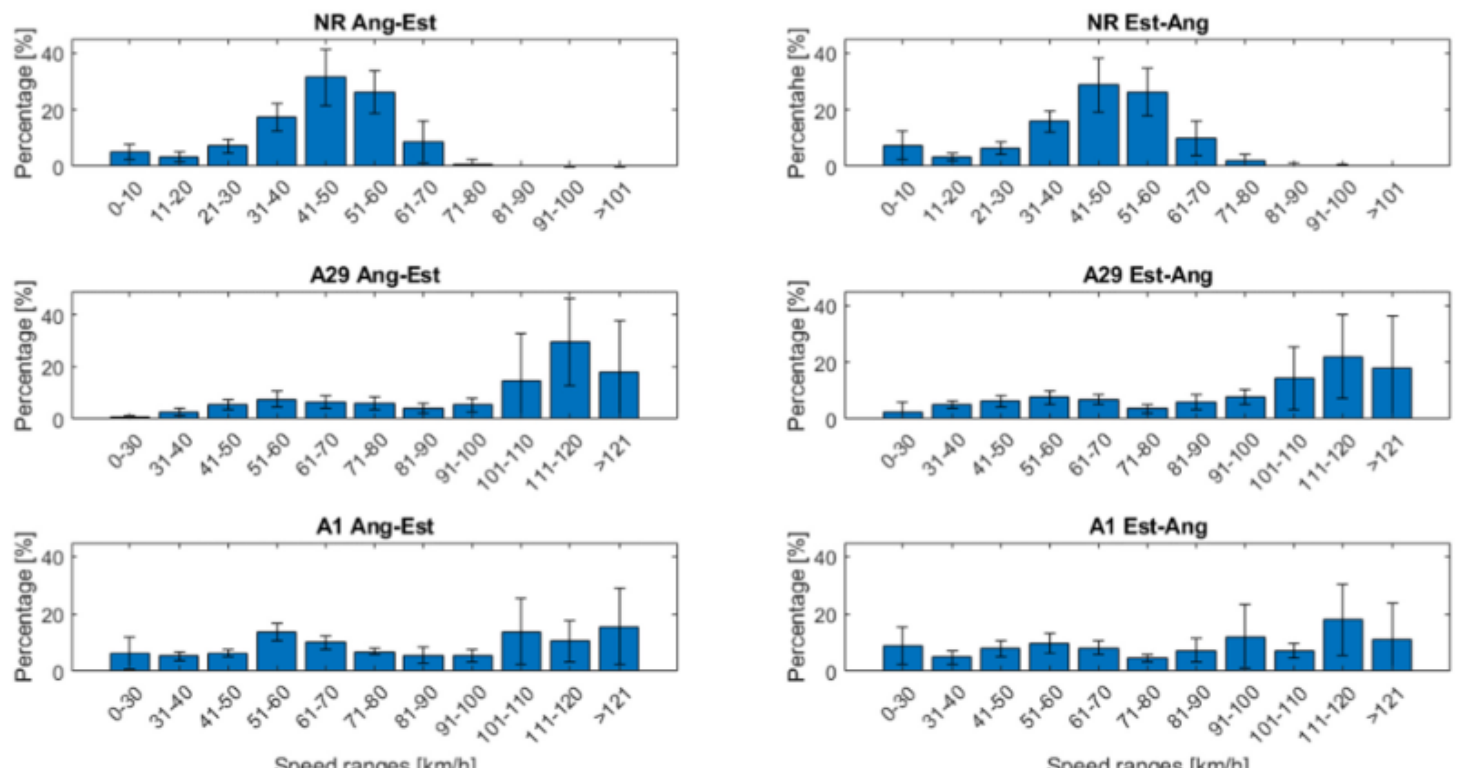

b)
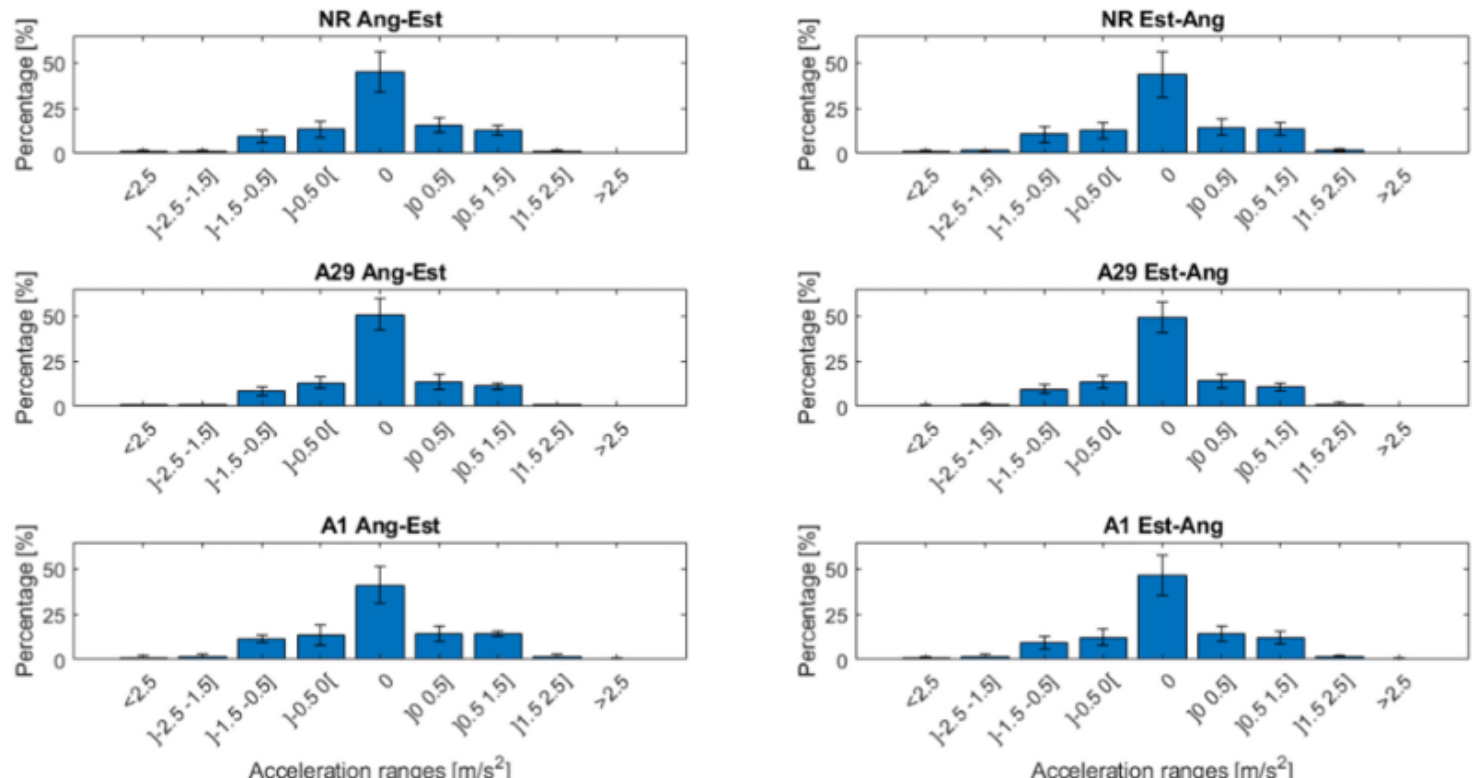

Fig. 5. Kinematic parameters distribution (with standard deviation values): a) Speed; and b) Acceleration. 

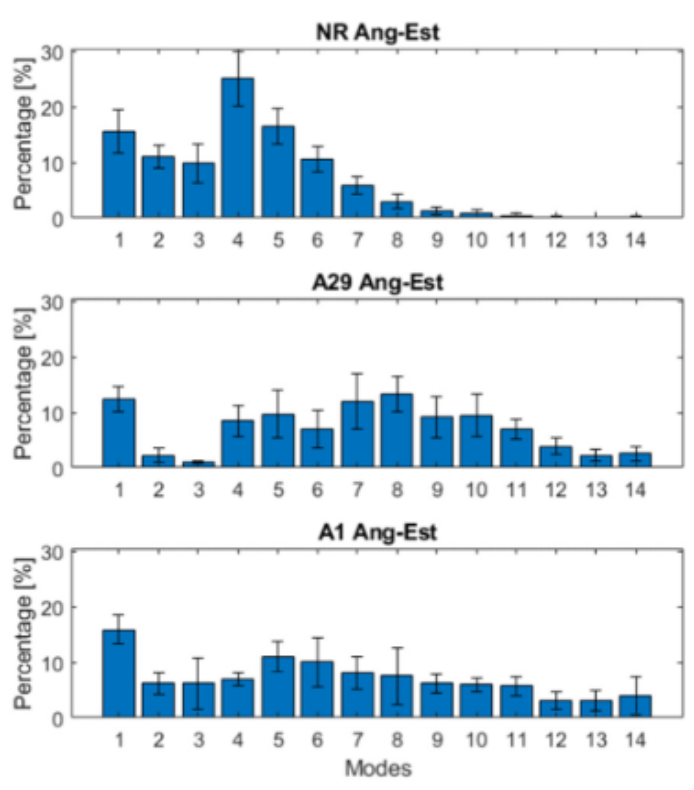

Fig. 6. VSP modes distribution (with standard deviation values).
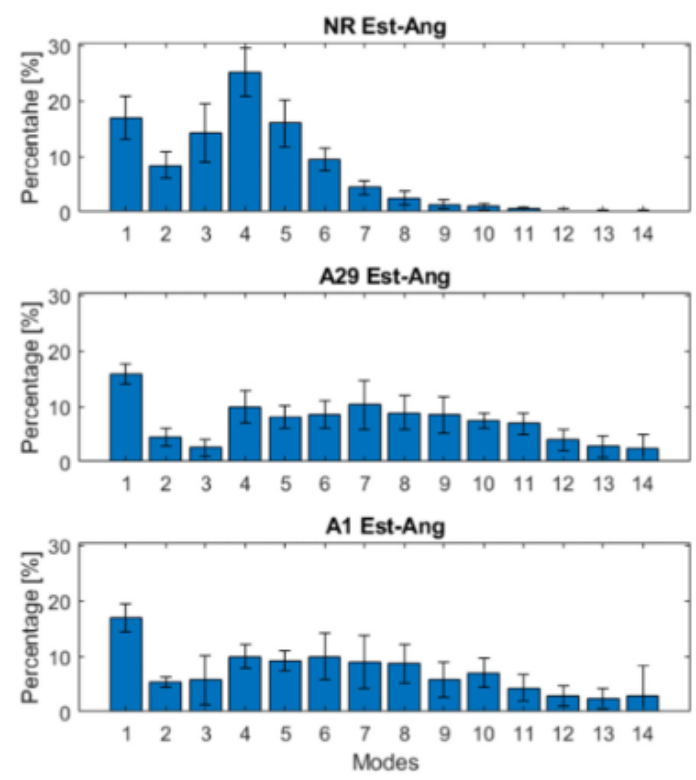

Bearing this in mind, VSP modes distributions were computed from the number of seconds spent in each mode in a trip conducted on a selected road. Then, this value was summed with those related to the same mode for all the other trips performed on the selected road type. Finally, this sum was divided by the travel time sum of all the runs related to the same route.

It can be noted that the percentage time spent in positive acceleration results to be higher on the National Road compared to the two highways (around 30\% and $25 \%$, respectively). These values have also to be contextualized considering the travel times were on average 1000,550 and $740 \mathrm{~s}$ on the National Road, A29 and A1, respectively.

As mentioned before, the first two modes are related to deceleration phases, the third to low-speed movements, and the others to acceleration phases. On the National Road the percentage time spent in mode 3 was equal to 10\%, higher than A29 (2\%) and A1 (5\%). Technically, this represents the elapsed time in idling (that occurs mostly in stop situations at roundabouts and traffic lights), and inevitably has contributed to the results explanation.

Finally, it is worth specifying that the transition from mode 4 to 14 leads to an increasing of the related emission factor. Even if the last five modes are more stressed on the highways, they are also in turn associated with permanence percentages turn out to be low (below 7\%). This can be due to the relative moderate average speed maintained by the drivers on the highways ( 95 and $80 \mathrm{~km} / \mathrm{h}$ for A29 and A1, respectively) associated with low speed-variations frequencies.

It must be noted that there is variability in terms of pollutant emissions between the testing vehicles, even if three of them present the same powertrain and European Emission Standard. In fact, several vehicle characteristics play a fundamental role in pollutant production, such as engine size, number of cylinders, cylinder-surface-volume ratio, gear ratios, air-fuel ratio, aerodynamics, and weight. All this information is considered by the VSP emission factors that in turn are estimated, for each vehicle, through a data collection with the combined use of an OBD and the PEMS, as described in Fernandes et al., 2019a, Fernandes et al., 2021.

\subsection{Discussion}

Vehicle speed is the main variable in noise estimation through NEMs and it plays a fundamental role in all situations (cruising, acceleration, and deceleration phases). On the contrary, the speed value assumes the main role in pollutant emissions evaluation through VSP methodology mostly in acceleration phases. In fact, in cruising condition, the influence of the speed on VSP values is not excessively strong (VSP increases by $23 \%$ passing from 1 to 120 $\mathrm{km} / \mathrm{h}$ ). In the high acceleration ranges (above $1 \mathrm{~m} / \mathrm{s} 2$ ), instead, the influence of speed on VSP becomes relevant: for instance, fixing the acceleration at $2 \mathrm{~m} / \mathrm{s}^{2}$, VSP increases by $138 \%$ passing 
from 1 to $120 \mathrm{~km} / \mathrm{h}$. This also matches with the results that show less CO2 and NOx emissions per kilometre on the highways due to a more steady-state driving behaviour, with less time spent in positive acceleration manoeuvres and in idling.

From the analysis of the results, the NEMs estimated that the higher production of noise emissions is expected to be along the highways. This can be led back to the higher speed maintained compared to the National Road. On the other hand, the higher emissions per kilometre in terms of $\mathrm{CO}_{2}$ and NOx computed with VSP methodology are predicted to be along the National Road. This could be explained with the fact that drivers variated the speed with higher frequency along the National Road than the highways, even though vehicles were driven at higher speeds along highways.

Although the acceleration has a strong influence on VSP in all speed ranges, the same does not happen for the noise. It must be highlighted that the noise produced by a vehicle can be divided into two contributions: engine and rolling. The first one, predominant up to $50 \mathrm{~km} / \mathrm{h}$, is affected by acceleration. In fact, high speed-variation frequencies lead to continuous engine loading and unloading cycles and as consequence strong variations in terms of noise levels. Moving to higher speeds, the engine contribution is covered by the rolling one that is more affected by the speed values than acceleration. Models such as Harmonoise and NMPB, indeed, provide to give more prominence to acceleration influence on noise at low-speed ranges than the high ones.

The lack of consolidated models able to consider acceleration can involve an underestimation of noise in urban scenarios. Moreover, Harmonoise was progressively substituted by CNOSSOS, even if this latter does not present a correction term in which the acceleration explicitly appears. Finally, VNSP is the only tested NEM that considers, as the VSP, the vehicle powertrain. This allows to capture the differences in terms of noise emissions between vehicles belonging to the same category.

\subsection{Statistical analysis}

The second-by-second noise and pollutant emissions evaluation allows to find the relative critical hotspots along a travel. Before proceeding with the noise and emissions mapping, a Spearman correlation analysis was performed between $\mathrm{L}_{\mathrm{w}}$ values, estimated with NEMS, and VSP ones, as depicted in Fig. 7.

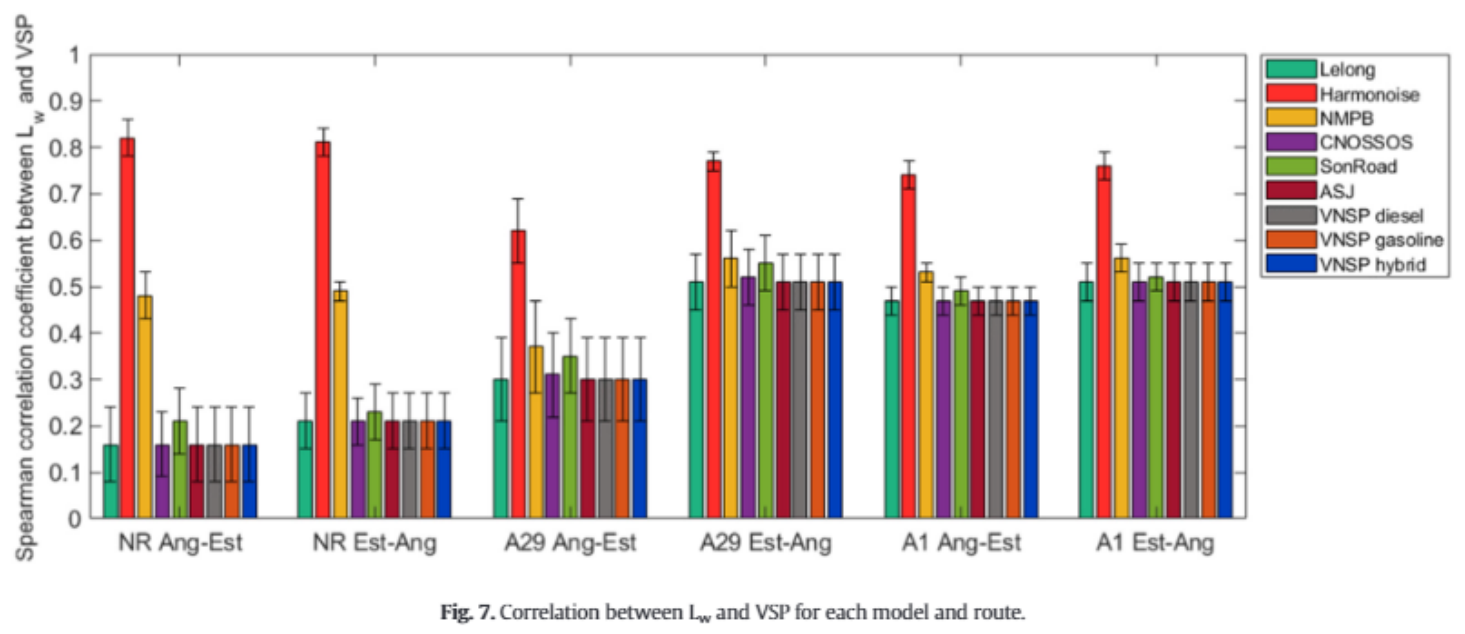

The coefficients are positive in all cases. Low correlation coefficients are detected along the National Road (below 0.2), except for Harmonoise and NMPB ( 0.8 and 0.5 , respectively). In fact, these two latter models, as the VSP, can follow the trend of the acceleration recorded during a travel (see Fig. 8). It can also be found that the coefficients related to NMPB are lower than Harmonoise inasmuch the first copies only the acceleration peaks but not the deceleration valleys. Moving on the highways, the correlation increases for the other models, reaching values close to 
0.5. In this type of roads, as well known, speed variations are smoother and, there is more agreement between the trends followed by noise levels and VSP. Interestingly, correlation coefficients related to A29 Ang-Est are lower than those related to A29 Est-Ang, which can be explained in the speed distributions along these routes. In fact, on A29 Ang-Est, the drivers spent more time in speeds higher than $100 \mathrm{~km} / \mathrm{h}(53 \%)$ as compared to the opposite direction (40\%), as it is possible to see in Fig. 5. The slight acceleration manoeuvres at higher speeds on A29 AngEst have led to obtain appreciable variations in terms of VSP but not in terms of $\mathrm{L}_{\mathrm{w}}$. On the other hand, on A29 Est-Ang, the slight acceleration and deceleration phases at slightly lower speeds have implied variations both in terms of VSP and $\mathrm{L}_{\mathrm{w}}$ during the travels and, consequently, higher correlation coefficients. The correlation coefficients related to Harmonoise on the highways are lower compared to those computed on the National Road. This happens because at high speed, the transition from a cruising condition to an acceleration phase did not result in significant fluctuations of $\mathrm{L}_{\mathrm{w}}$ and, on the other hand, in considerable variations of VSP values. Results also indicated that SonRoad model (with a road slope correction term) presents a slightly higher correlation coefficients compared to the other models used without any correction term. This was due to the fact that most of roads on studied routes are flat. 

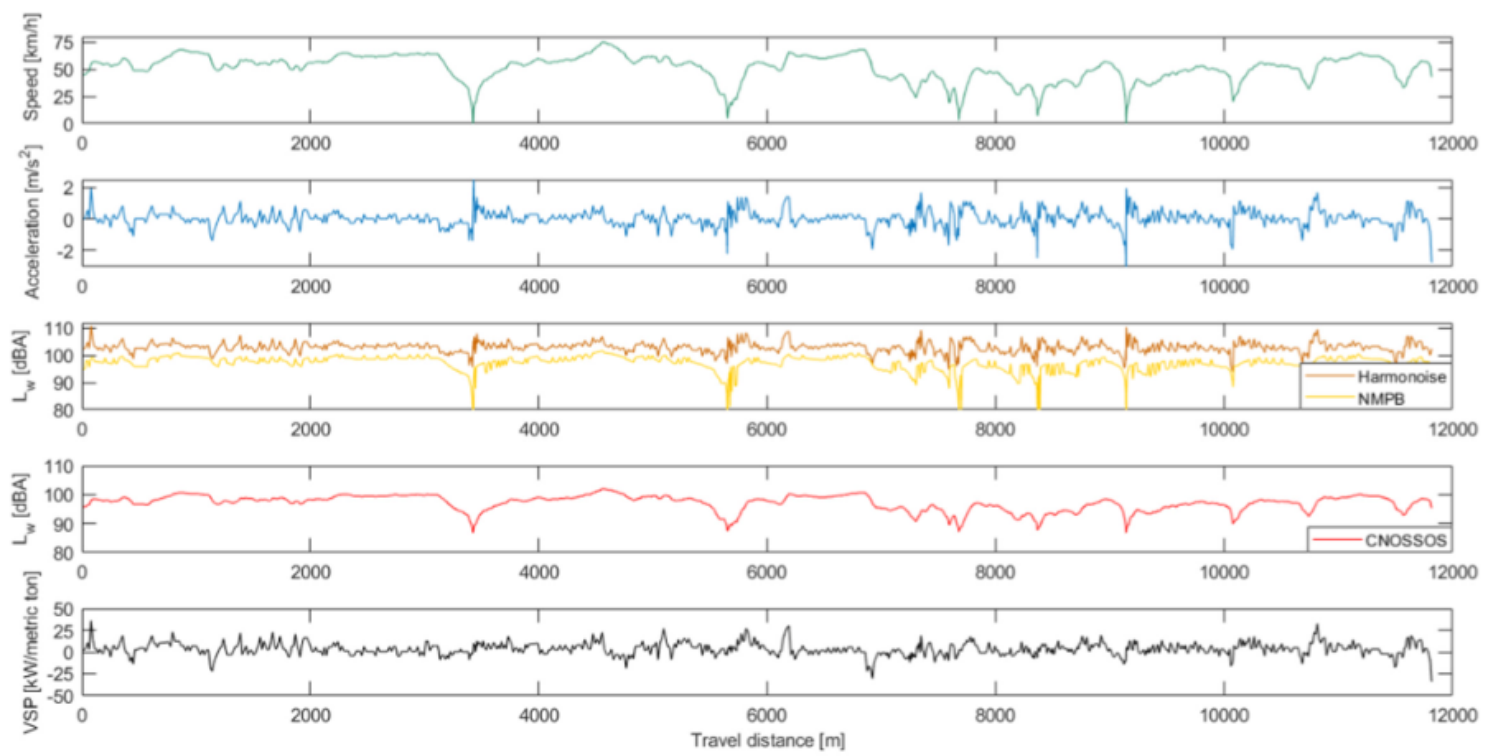

b)
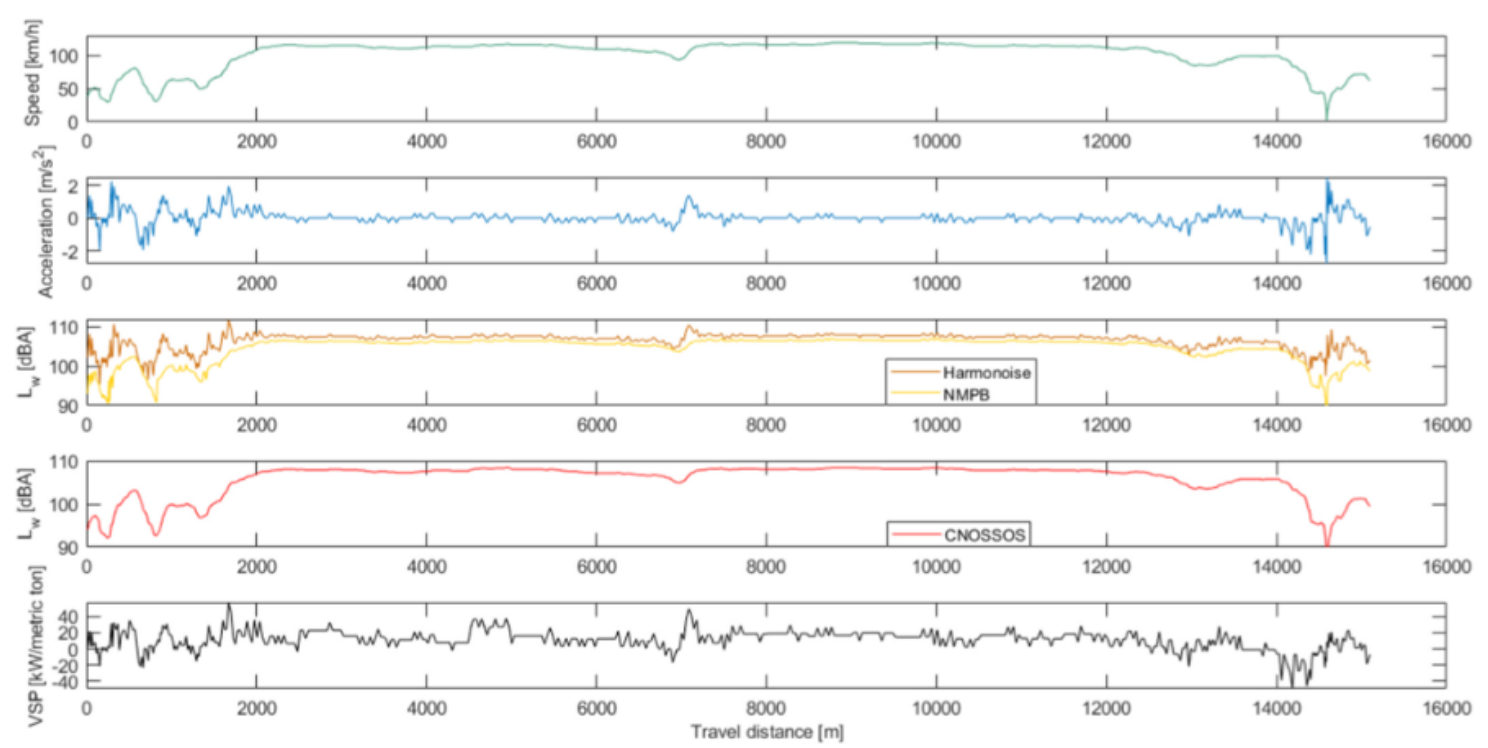

Fig. 8. Speed, acceleration, noise and VSP signals along: a) National Road and b) highway.

\subsection{Noise and pollutant emissions critical hotspots}

Maps were created through a GIS platform using the following inputs: i) GPS coordinates; ii) noise levels estimated through Harmonoise and CNOSSOS; iii) VSP values. CNOSSOS (used without corrections expressed by Eqs. (2), (3)) was selected as reference for all the other models that do not present acceleration correction terms.

Fig. 9 presents an example of noise and VSP mapping for a segment of the National Road. Generally, in correspondence of roundabouts, traffic intersections and turning, engine noise contribution is predominant since the speed is not excessively high while sharp acceleration episodes can appear. Therefore, Harmonoise, because of its acceleration correction term, tends to estimate higher noise levels downstream intersections (see Fig. 9a). CNOSSOS (and other models) could underestimate noise in these points by not taking acceleration into account. From 
Fig. 9b, it can be noted that noise values decrease while vehicle is approaching roundabout and accelerating while leaving the roundabout because of low speeds (the main input variable in CNOSSOS) at those areas. On the other hand, the strong variations of speed negatively affect the pollutant emissions in an urban environment. Thus, VSP maps have a greater similarity with Harmonoise one, confirming the higher correlation computed along the National Road.

a)

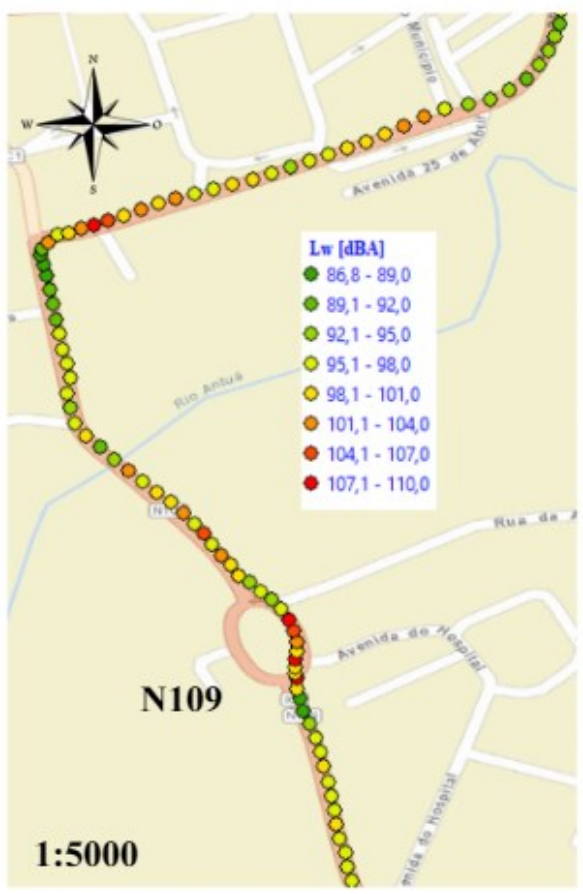

b)

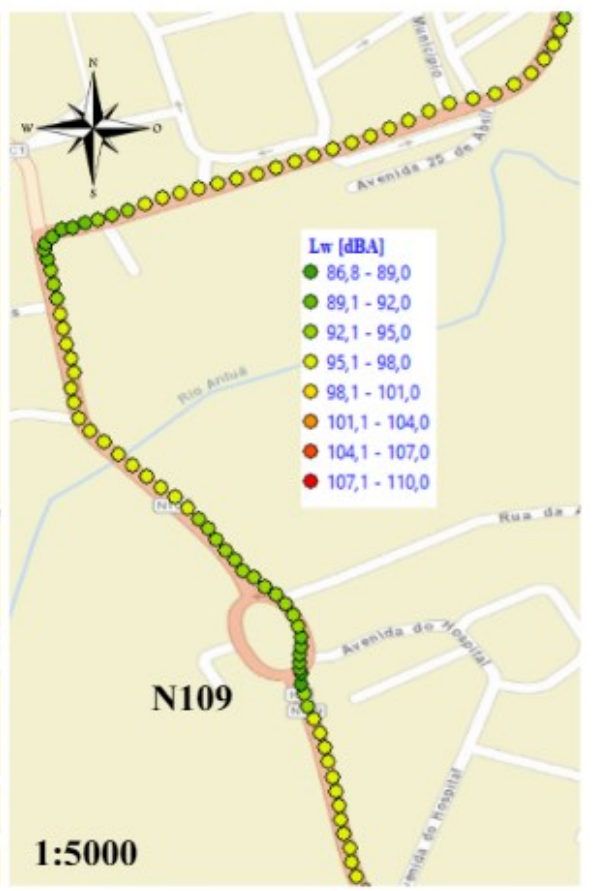

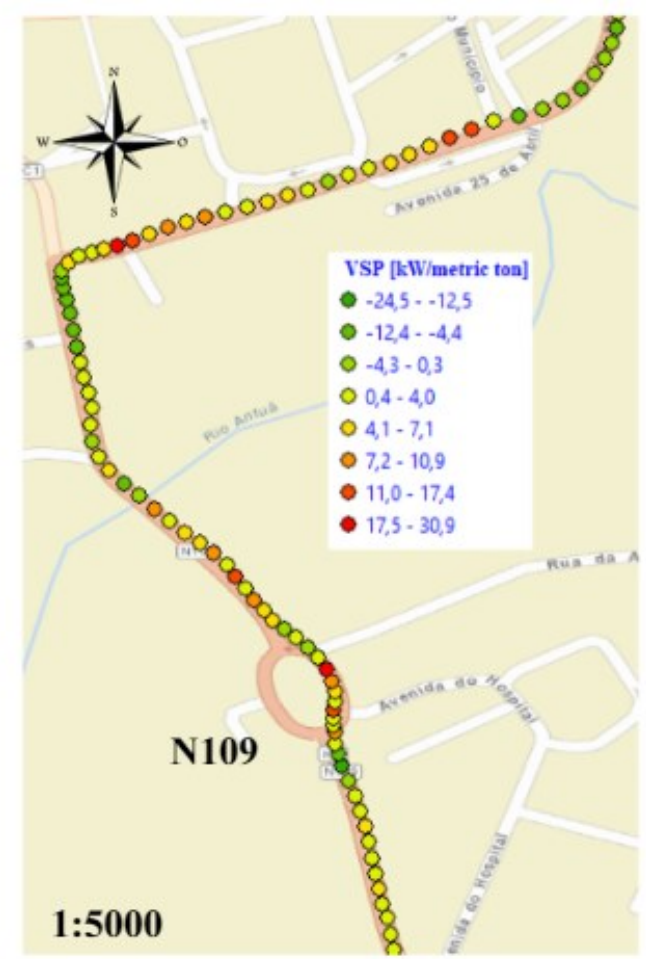

Fig. 9. Maps for a section of the National Road: a) Harmonoise; b) CNOSSOS; and c) VSP.

Maps related to highways (Fig. 10) show a different trend. Due to the higher speed, rolling noise contribution becomes predominant and the influence of acceleration on noise tends to 
disappear. Hence, maps built with Harmonoise and CNOSSOS result to be more similar between them, with presence of critical hotspots due to the high-speed effect on noise. On the contrary, the maps built through VSP present a stronger variability in terms of hotspots. In fact, in this latter case, the map points are associated with both low and high VSP values (from -52.4 to 83.1 $\mathrm{kW} /$ metric ton). This is due to the VSP sensibility to the smooth acceleration and deceleration episodes at high speeds.

a)

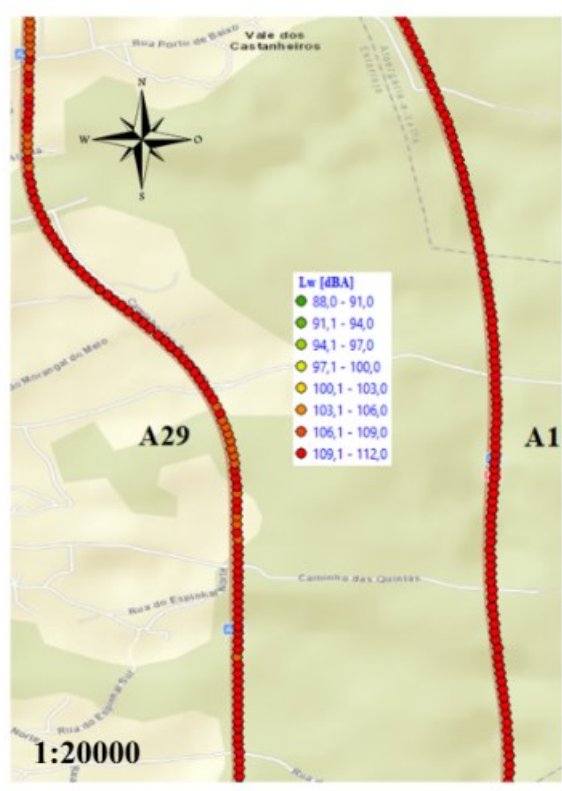

b)

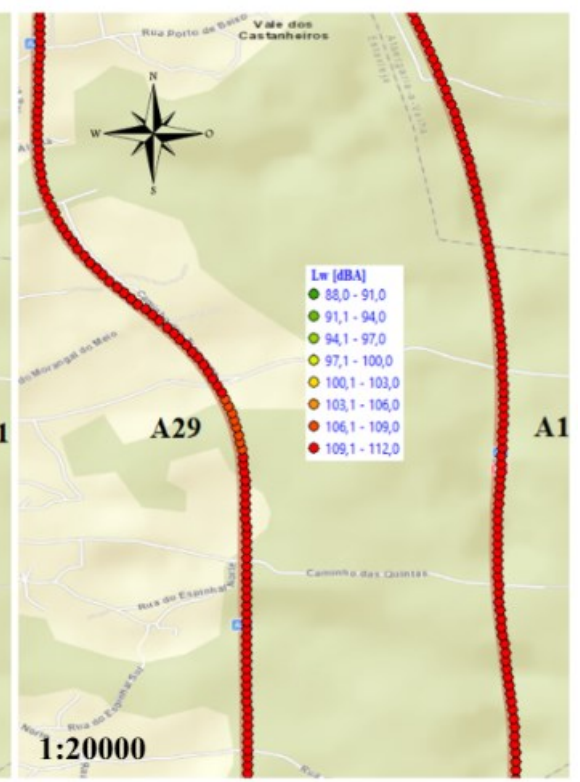

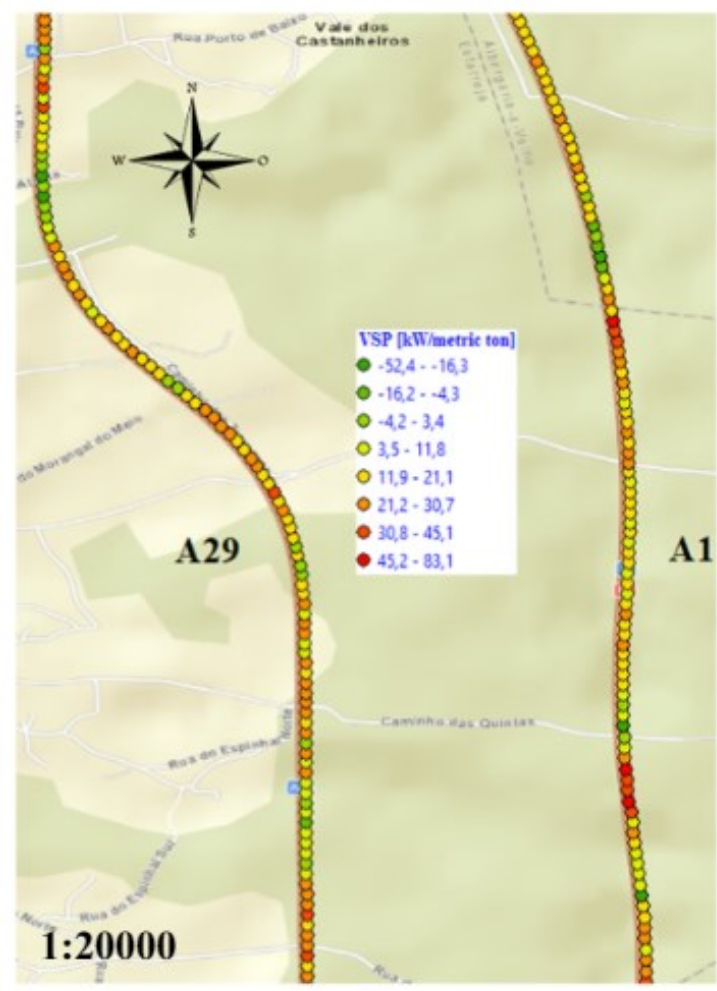

Fig. 10. Maps for a section of A29 and A1: a) Harmonoise; b) CNOSSOS; and c) VSP. 


\section{Conclusions}

In this paper, seven NEMs and the VSP methodology were employed to assess noise and pollutants emissions, produced by a single vehicle along several trips on a National Road and two highways, focusing on the role of parameters in what respected to the vehicle speed, acceleration and road slope and their impact on the models.

Harmonoise and NMPB can take the acceleration into account through correction terms. The first tends to emphasize the noise levels in the acceleration phases and to reduce them in the deceleration ones, while NMPB model exalts the vehicle noise emissions even in deceleration phase (due to the engine brake noise contribution). Although Lelong presents an acceleration correction terms as well, its use has not provided significant variations in terms of average sound power levels. CNOSSOS and SonRoad consider road slope correction terms. It is worth mentioning that the first derives from Harmonoise model but, it does not fully inherit the acceleration correction term. Finally, VNSP considers the noise emissions variability of vehicles belonging to the same category by using powertrain information.

Acceleration seems to have a strong impact on noise models at low-speed range (due to the predominance of the engine noise contribution), while at the higher one its effect tends to disappear because of the greater contribution of rolling noise. This is in contrast with what happens with VSP where a transition from a cruising condition to an acceleration phase at high speeds leads to a strong increasing of VSP values.

Another conclusion from this research is that noise models with acceleration correction terms estimate $\mathrm{L}_{\mathrm{w}}$ values that have positive moderate-to-high correlation with VSP ones in all situations; moreover, they can detect roundabouts and other traffic singularities as critical hotspots. The other noise models do not provide the same results, and this may result in imprecise estimation of noise pollution at those locations. However, Harmonoise model estimates higher noise emissions along the National Road compared the others NEMs. Hence, the development of new NEMs able to provide a more accurate estimation of vehicle sound power levels in nonsteady state driving conditions is strongly needed.

Results indicated that the higher values of noise emissions are expected to be on the two highways due to higher speeds, while more $\mathrm{CO}_{2}$ and NOx per kilometre emissions are estimated to be produced along the National Road, because of more frequent sharp-acceleration episodes. It must be underlined that these results are valid for the selected case study and could vary for other roads with variations in speed limits, traffic and traffic control treatments. However, the proposed methodology could be replicated and extended to different case studies by: 1) computing VSP emission factors of the testing vehicles; 2) retrieving vehicle-kinematic data and road grade information from OBD and GPS, respectively; 3) estimating $\mathrm{L}_{\mathrm{w}}$ and VSP, $\mathrm{CO}_{2}$ and NOx on a second-by-second time basis, through the respective models. Moreover, this methodology can be easily integrated in a smart mobility tool inasmuch it can take information from the vehicles OBD plug. Single-vehicle noise and exhaust emissions can be used as framework for the building of road traffic flow related maps by using interpolation and spatialization techniques. This would be in turn helpful both for policymakers and road users. The first group can use the tool to detect critical hotspots and to elaborate plans for the reduction of noise and pollutant emissions in specific places. Moreover, based on the values recorded (in terms of noise, emissions, travel time), a classification could be associated to a certain street and consequentially the road user could choose the best option.

Future work consists in associating a noise propagation model to each NEM, leading to several different Road Traffic Noise Models (RTNMs). They, sub-sequentially, will be tested by using both aggregated and microscopic traffic data along urban road segments and highways. The results can be compared with field measurements with the aim to verify which model performs better in each scenario. 


\section{Acknowledgements}

The authors acknowledge the financial support of the following projects: UIDB/00481/2020 and UIDP/00481/2020 - FCT - Fundação para a Ciência e a Tecnologia; and CENTRO-01-0145-FEDER-022083 - Centro Portugal Regional Operational Programme (Centro2020), under the PORTUGAL 2020 Partnership Agreement, through the European Regional Development Fund; MobiWise (P2020 SAICTPAC/0011/2015), co-funded by COMPETE2020, Portugal2020 - Operational Program for Competitiveness and Internationalization (POCI), European Union's ERDF (European Regional Development Fund), and FCT; DICA-VE (POCI-01-0145-FEDER-029463), funded by FEDER through COMPETE2020, and by National funds (OE), through FCT/MCTES. A. Pascale acknowledges the support of FCT for the Scholarship 2020.05106.BD.

\section{References}

A.R. Anya, H.C. Frey, B. Liu. Method and case study for quantifying local emissions impact of transportation improvement project involving road realignment and conversion to multilane roundabout. Pap. Present. 92nd Annu. Meet. Transp. Res. Board, Washington, DC, US, Pap. 13-5243 (2013)

W. Babisch. Updated exposure-response relationship between road traffic noise and coronary heart diseases: a meta-analysis. Noise Health, 16 (2014), pp. 1-9, 10.4103/14631741.127847

D. Banerjee. Road traffic noise exposure and annoyance: a cross-sectional study among adult Indian population. Noise Health, 15 (2013), pp. 342-346, 10.4103/1463-1741.116583

Bernhard, R., Wayson, R.L., 2005. An introduction to tire/pavement noise of asphalt pavement.

F. Besnard, J.-F. Hamet, J. Lelong, E. Le Duc, V. Guizard, N. Fürst, S. Doisy, G. Dutilleux. Road noise prediction. 1 - calculating sound emission from road traffic. Methodol. Guid. Sétra (2009), p. 124.

A. Can, P. Aumond. Estimation of road traffic noise emissions: the influence of speed and acceleration. Transp. Res. D Transp. Environ., 58 (2018), pp. 155$171, \underline{10.1016 / j \cdot \operatorname{trd} .2017 .12 .002}$

A. Can, L. Leclercq, J. Lelong. Dynamic estimation of urban traffic noise: influence of traffic and noise source representations. Appl. Acoust., 69 (2008), pp. 858867, 10.1016/j.apacoust.2007.05.014

A. Can, A. L'Hostis, P. Aumond, D. Botteldooren, M.C. Coelho, C. Guarnaccia, J. Kang. The future of urban sound environments: impacting mobility trends and insights for noise assessment and mitigation. Appl. Acoust., 170 (2020), 10.1016/j.apacoust.2020.107518

M.C. Coelho, T.L. Farias, N.M. Rouphail. A numerical tool for estimating pollutant emissions and vehicles performance in traffic interruptions on urban corridors. Int. J. Sustain. Transp., 3 (4) (2009), pp. 246-262, 10.1080/15568310802175641

B. De Coensel, A.L. Brown, D. Tomerini. A road traffic noise pattern simulation model that includes distributions of vehicle sound power levels. Appl. Acoust., 111 (2016), pp. 170178, 10.1016/j.apacoust.2016.04.010. 
G. Dutilleux, J. Defrance, D. Ecotière, B. Gauvreau, M. Bérengier, F. Besnard, E. Le Duc. NMPB-routes-2008: the revision of the french method for road traffic noise prediction. Acta Acust. United Acust., 96 (2010), pp. 452-462, 10.3813/AAA.918298

European Environment Agency, 2017. Exposure of Europe's population to environmental noise [WWW Document]. URL https://www.eea.europa.eu/data-and-maps/indicators/exposure-toand-annoyance-by-2.

European Environment Agency. Emissions of air pollutants from transport. Indic. Assess., 12 (2018), 10.1088/0004-637X/705/2/L195

European Environment Agency. Air Quality in Europe - 2019 Report. EEA (2019)

European Environment Agency, 2019b. Total greenhouse gas emission trends and projections in Europe.

European Environment Agency. Environmental Noise in Europe - 2020. European Environment Agency (2020), 10.2800/686249

P. Fernandes, T. Fontes, S.R. Pereira, N.M. Rouphail, M.C. Coelho. Multicriteria assessment of crosswalk location in urban roundabout corridors. Transp. Res. Rec., 2517 (2015), pp. 37$47, \underline{10.3141 / 2517-05}$

P. Fernandes, K. Salamati, N.M. Rouphail, M.C. Coelho. Identification of emission hotspots in roundabouts corridors. Transp. Res. D Transp. Environ., 37 (2015), pp. 4864, 10.1016/j.trd.2015.04.026

P. Fernandes, M.C. Coelho, N.M. Rouphail. Assessing the impact of closely-spaced intersections on traffic operations and pollutant emissions on a corridor level. Transp. Res. D Transp. Environ., 54 (2017), pp. 304-320, 10.1016/j.trd.2017.05.016

P. Fernandes, J. Teixeira, C. Guarnaccia, J.M. Bandeira, E. Macedo, M.C. Coelho. The potential of metering roundabouts: influence in transportation externalities. Transp. Res. Rec., 2672 (2018), pp. 21-34, 10.1177/0361198118774667

P. Fernandes, E. Macedo, B. Bahmankhah, R.F. Tomas, J.M. Bandeira, M.C. Coelho. Are internally observable vehicle data good predictors of vehicle emissions? Transp. Res. D Transp. Environ., 77 (2019), pp. 252-270, 10.1016/j.trd.2019.11.004

P. Fernandes, M. Vilaça, E. Macedo, C. Sampaio, B. Bahmankhah, J.M. Bandeira, C. Guarnacci a, S. Rafael, A.P. Fernandes, H. Relvas, C. Borrego, M.C. Coelho. Integrating road traffic externalities through a sustainability indicator. Sci. Total Environ., 691 (2019), pp. 483498, 10.1016/j.scitotenv.2019.07.124

P. Fernandes, R. Tomás, F. Acuto, A. Pascale, B. Bahmankhah, C. Guarnaccia, A. Granà, M.C. Coelho. Impacts of roundabouts in suburban areas on congestion-specific vehicle speed profiles, pollutant and noise emissions: an empirical analysis. Sustain. Cities Soc., 62 (2020), p. $102386,10.1016 / \mathrm{j} . \mathrm{scs} .2020 .102386$

P. Fernandes, R. Tomás, E. Ferreira, B. Bahmankhah, M.C. Coelho. Driving aggressiveness in hybrid electric vehicles: assessing the impact of driving volatility on emission rates. Appl. Energy, 284 (2021), p. 116250, 10.1016/j.apenergy.2020.116250

G. Graziuso, S. Mancini, C. Guarnaccia. Comparison of single vehicle noise emission models in simulations and in a real case study by means of quantitative indicators. Int. J. Mech., 14 (2020), 10.46300/9104.2020.14.26 
C. Guarnaccia. EAgLE: equivalent acoustic level estimator proposal. Sensors, 20 (3) (2020), p. $701, \underline{10.3390 / \mathrm{s} 20030701}$

C. Guarnaccia, J. Bandeira, M.C. Coelho, P. Fernandes, J. Teixeira, G. Ioannidis, J. Quartieri. Statistical and semi-dynamical road traffic noise models comparison with field measurements. AIP Conf. Proc (2018), 10.1063/1.5045445

J.I. Halonen, H.M. Dehbi, A.L. Hansell, J. Gulliver, D. Fecht, M. Blangiardo, F.J. Kelly, N. Cha turvedi, M. Kivimäki, C. Tonne. Associations of night-time road traffic noise with carotid intima-media thickness and blood pressure: the Whitehall II and SABRE study cohorts. Environ. Int., 98 (2017), pp. 54-61, 10.1016/j.envint.2016.09.023

K. Heutschi. SonRoad: new swiss road traffic model. Acta Acust. United Acust., 90 (2004), pp. $548-554$

Instituto da Mobilidade e dos Transportes, I.P. Relatório de Tráfego Na Rede Nacional de Autoestradas $4^{\circ}$ Trimestre de 2018 (2018)

T.A. Jacobson, J.S. Kler, M.T. Hernke, R.K. Braun, K.C. Meyer, W.E. Funk. Direct human health risks of increased atmospheric carbon dioxide. Nat. Sustain., 2 (2019), pp. 691701, 10.1038/s41893-019-0323-1

S. Kephalopoulos, M. Paviotti, F. Anfosso-Lédée. Common noise assessment methods in Europe (CNOSSOS-EU). EUR 25379 EN, Publications Office of the European Union, Luxembourg (2012), 10.2788/31776

J. Lelong. Vehicle Noise Emission: Evaluation of Tyre/Road and Motor-Noise Contributions. Internoise Conf (1999)

R. O'Driscoll, M.E.J. Stettler, N. Molden, T. Oxley, H.M. ApSimon. Real world CO2 and NOx emissions from 149 Euro 5 and 6 diesel, gasoline and hybrid passenger cars. Sci. Total Environ., 621 (2018), pp. 282-290, 10.1016/j.scitotenv.2017.11.271

R.L. Ott, M.T. Longnecker. An Introduction to Statistical Methods and Data Analysis. Cengage Learn (2008).

A. Pascale, P. Fernandes, B. Bahmankhah, E. Macedo, C. Guarnaccia, M.C. Coelho. A vehicle noise specific power concept. Forum Integr. Sustain. Transp. Syst. IEEE ISTS 2020 (2020), pp. 170-175, 10.1109/fists46898.2020.9264899

M. Pedersen, T.I. Halldorsson, S.F. Olsen, D. Hjortebjerg, M. Ketzel, C. Grandström, O. Raasch ou-Nielsen, M. Sørensen. Impact of road traffic pollution on pre-eclampsia and pregnancyinduced hypertensive disorders. Epidemiology, 28 (2017), pp. 99106, 10.1097/EDE.0000000000000555

J.L. Peel, R. Haeuber, V. Garcia, A.G. Russell, L. Neas. Impact of nitrogen and climate change interactions on ambient air pollution and human health. Biogeochemistry, 114 (2013), pp. 121-134, 10.1007/s10533-012-9782-4

J. Quartieri, N.E. Mastorakis, G. Iannone, C. Guarnaccia, S.D. Ambrosio, A. Troisi, T.L.L. Lenza A review of traffic noise predictive noise models. Recent Adv. Appl. Theor. Mech. (2009), pp. $72-80$

J. Quartieri, G. Iannone, C. Guarnaccia. On the improvement of statistical traffic noise prediction tools. Proc. 11th WSEAS Int. Conf. Acoust. Music Theory Appl. AMTA '10 (2010), pp. 201-207 
K. Salamati, N.M. Rouphail, H.C. Frey, B. Liu, B.J. Schroeder. Simplified method for comparing emissions in roundabouts and at signalized intersections. Transp. Res. Rec., 2517 (2015), pp. 48-60, 10.3141/2517-06

G. Sandhu, H. Frey. Effects of errors on vehicle emission rates from portable emissions measurement systems. Transp. Res. Rec., 2340 (1) (2013), pp. 10-19, 10.3141/2340-02

D. Singh, N. Kumari, P. Sharma. A review of adverse effects of road traffic noise on human health. Fluct. Noise Lett., 17 (2018), pp. 1-12, 10.1142/S021947751830001X

C. Steele. A critical review of some traffic noise prediction models. Appl. Acoust., 62 (3) (2001), pp. 271-287, 10.1016/S0003-682X(00)00030-X

S. Turner. Travel Time Data Collection Handbook: Office of Highway Information Management. Federal Highway Administration, U.S. Department of Transportation (1998)

US EPA. Methodology for developing modal emission rates for EPA's multi-scale motor vehicle \& equipment system. Prep. by North Carolina State Univ. US Environ. Prot. Agency, EPA420, Ann Arbor, MI (2002)

Watts, G., 2005. Harmonoise Prediction Model for Road Traffic Noise. Publ. Proj. Rep. PPR 034, TRL.

K. Yamamoto. Road traffic noise prediction model "ASJ RTN-Model 2008": report of the research committee on road traffic noise. Acoust. Sci. Technol., 31 (2010), pp. 2$55, \underline{10.1250 / \text { ast. } 31.2}$

W. Yuan, H.C. Frey, T. Wei, N. Rastogi, S. VanderGriend, D. Miller, L. Mattison. Comparison of real-world vehicle fuel use and tailpipe emissions for gasoline-ethanol fuel blends. Fuel, 249 (2019), pp. 352-364, 10.1016/j.fuel.2019.03.115

Z. Zhai, R. Tu, J. Xu, A. Wang, M. Hatzopoulou. Capturing the variability in instantaneous vehicle emissions based on field test data. Atmosphere, 11 (2020), 10.3390/ATMOS11070765 